UCLA/PPG -1123

DE8B 005880

\title{
HYDROGEN PUMPING AND RELEASE BY GRAPHITE UNDER HIGH FLUX PLASMA BOMBARDMENT
}

\author{
Y. Hirooka*, W.K. Leung*, R.W. Conn*, D.M. Gocbci*, \\ B. LaBombard*, R. Nygren*, and K.L. Wilson**
}

UCLA-PPG-1123 January. 1988

\author{
- Institute of Plasma and Fusion Research \\ Department of Mechanical, Acrospace and Nuclcar Engincering \\ University of Califomia, Los Angcles \\ Los Angeles, California 90024
}

* Physical Researct: Division

Sandia National Laboratorics

Livermore. California 94550

\section{DISCLAIMER}

This repon was prepared as an account of work sponsofed by an agency of the Urrited States Government. Neinher the Uniled States Goverament nor any agency thereol, nor any of their employees, makes any warranty, express or implied, or assumes any legul liability or responsibility for the accuracy, completeness, or usefulness of any information, apparalus, product, or process disclised, as represents that is use would not infringe priyately unned riglits. Referелсе herein to any specifie commetcial product, process, or service by Ifade name, tridemark. manufaclurer, or otherwise does not necessarily constilute of imply its endursement, recommendation, of favoring by the Unitod States Government of any agency thereof. The views and opinions of authors expressed herein do not necessarily state or refect those of the United States Government or any agency thereof.

$$
\text { B: } \cdots
$$


Disclabitop

This Iepon was prepared as an accouns of work sponsored by an agency of the Unted Slates Ouvernment. Neulher the United

Siates Government nor any agency thereof, nor any of their cmployees, makes any warranty. express or implied, or assumes any lesal lisbility or responsibility for the accuracy. completeness, or uselulness of iny information, apparatus. product, or process disclosed, or represents thet its use would not infringe privasty owned rights. Reference herein to any specific commercial product, procers, or serviee by trade name, trademut. manufacturer, or aherwise, does not necessarily constitute of imply its endorsement, recommendstion. or favoring by the United States Government or any agency thereof. The views end opinuons of luthors expressed herein do not necessafily state or reftect those of the United States Govemment or any agency thereof. 


\section{ABSTRACT}

Inert gas (helium or argon) plasma bombardment has been found to inctease the surface gas adsorptivity of isotropic graphite (POCO-graphite), which can then genler residual gases in a high vacuum system. The inert gas plasma bombardment was cartied out at a flux $=1 \times 10^{18}$ ions s $\mathrm{s}^{-1} \mathrm{~cm}^{-2}$ to a fluence of the order of $10^{21}$ ions $/ \mathrm{cm}^{2}$ and at temperatures around $800^{\circ} \mathrm{C}$. The plasma bombarding energy was varied between 100 and $200 \mathrm{eV}$. The gettering speed of the activated graphite surface is estimated to be as large as 25 liters $\mathrm{s}^{-1} \mathrm{~cm}^{-2}$ at total pressures between $10^{-6}$ and $10^{-7}$ orr. The gettering capacity estimaled is 0.025 torr-liter $/ \mathrm{cm}^{2}$ at room temperature. The gettering capability of graphite can be easily recovered by repealing inen gas plasma bombardment. The activated graplute surface exhibits a smooth, sponge-like morphology with significantly increased porc: openings, which correlutes with the observed increase in the surface gas adsorptivity.

The activated graphite surface has been observed to pump hydrogen plasma particles as well. From calibtated $H$-alpha measurements, the dynamic hydrogen retention capacity is evaluated to be as large as $2 \times 10^{18} \mathrm{H} / \mathrm{cm}^{2}$ at temperatures below $100{ }^{\circ} \mathrm{C}$ and at a plasma bombarding encrgy of $300 \mathrm{eV}$. The graphite temperature was varied between is and $480 \propto \mathrm{C}$. Due to the plasma particle pumping capability, hydrogen recycling from the activated graphite surface is significantly reduced, relative to that from a pre-saturated surface. A pre-saturated surface was also observed to reproducibly pump a hydrogen plasma to a concentration of $9.5 \times 1017 \mathrm{H} / \mathrm{cm}^{2}$. The hydrogen retention capacity of graphite is foltnd to decrease with increasing temperature. Actemperatures between 450 and $480^{\circ} \mathrm{C}$, the hydrosen retention estimated for the activaled surfare and pre-saluraled surface is $7.9 \times 10^{17} \mathrm{~J} / \mathrm{cin}{ }^{2}$ and $2.7 \times 10^{17} \mathrm{H} / \mathrm{cm}^{2}$, respectively. A transicnt pumping mechanism associated with the sponge-like surface morphology is conjectured to explain the large hydrogen relcmion capacity. Hydrogen release behavior under helium and argon plasma bombardment was also investigited, and the result indicated the pessibility of some in-pore retrapping effect. The effective plasma impact desorption cross sections ate Evaluated in the plasma boubarding energy range from 15 to $300 \mathrm{eV}$. A significant fraction (70).80\%) of pre-implanted hydrogen was observed wo release under inert gis plasma bon.

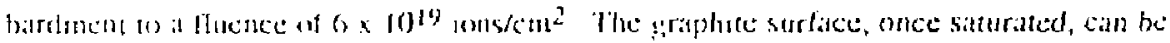

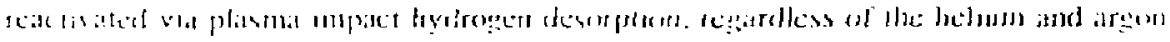

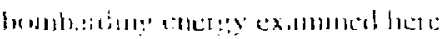




\section{INTEODUCTION}

Giraphitc is widely recognized as the most striblibe matedial for phismatiacing centpunents in cxisting atud near-term magnetic fusion devices. Majur wokanaks such its TFTR. 1 JET, ${ }^{2}$ DIII-D ${ }^{3}$ and TEXTOR ${ }^{4}$ have been sucecssfully operaring with graphite limiters and protective annors. Also, the first D-T ignition tokamak, ClT, is currently designed to use graphite as the plasma-facing material for all key in-vessel ccmponents, 5 These fusion applications of graphite were originally motivated by the physical properties including high heaf resistance and low atomic number, which are obviously superior to those of existing metals and alloys. In addition, another encouraging property of graphite has been discovered in recent plasma confinement experiments in TFTR ${ }^{6}$ and JET. ${ }^{7}$

In TFTR, after helium plasma discharge conditioning, graphite used as the toroidal bumper limiter at room temperature pumps a large influx of hydrogen plasma particles during confinement discharges. As a consequence, the hydrogen recycling rate in the edge:plasma region is significantly reduced, which then results in a high tcmperature corc plasma (ofren referred to as a 'Super Shot'). ${ }^{6}$ The reduced local recycling is postulated to occur along with refilling of the near-surface hydrogen trapping sites in graphite that are emptied during the He-plasma discharge conditioning.8,9 In JET, however, graphite tiles on the. inner toroidal wall are observed to reproducibly pump hydrogen plasma paricles without particular discharge conditioning 7 This has ied to an improvement of plasma parameters in confinement experiments. Currently proposed to explain the phenomenon observed in JET is a conpletcly different pumping mechanism, based on the transient particle flux inbalame: between fast implantation and relatively slow reemission from the griphite surface at temperitures around $300^{\circ} \mathrm{C} .10$

For these observations, the first noticeable difference can be lound in the states of hydrosen in graphite. In the case of TFTR, most plasma-implanted hydrogen parsicles ine bound to the trapping sites and few remain mobile in graplite whercas the oppostc is tuc for JET. The surface temperature appears to phy an importint role in detennining the statte of hydrogen in graphite and hence the behavior of hydrogen reemission. On the other hand, it is in common for these tokamaks that graphife components have been extensively

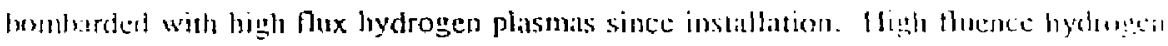

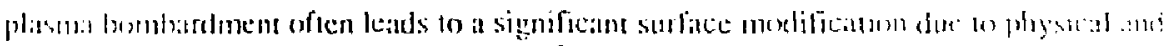

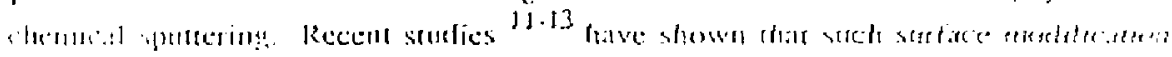

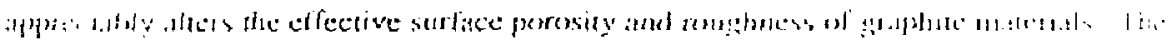

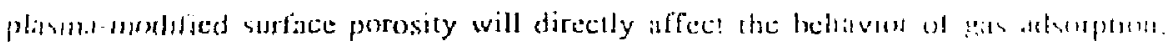

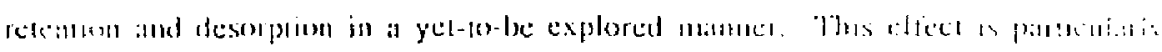


important for porous graphite materials. Yet the graphite materials, POCO AXF-5Q in TFTR and CL 5890 PT in JET have relatively high porosities of 20 to $30 \%$. These arguments naturally lead to a conjecture that the modified surface characteristics of graphite limiters might in part contribute to the plasma pumping effects observed in these tokamaks. Nevertheless, further investigation is necessary to understand the nature of pumping of plasma particles by graphite materials.

In the present work, the behavior of graphite under high flux, high fluence plasma bombardment has been studied using the PISCES-A facility. 14 For completeness of investigation, several series of experiments are conducted here, namely: (1) plasma activation of a graphite surface; (2) hydrogen recycling from an activated graphite surface; and ) hydrogen release from a saturated graphite associated with reactivation. Also, im . tant implications from the results to fusion experiments are discussed.

\section{EXPERMMENTAL}

\section{A. General experimental arrangement and procedure}

A schematic diagram of the experimental setup is shown in Fig.1. After ultrasonic cleaning in acetone, a disk specimen of POCO-graphite (grade: HPD-1, the porosity = $25 \%$ ) with a typical diameter of $4.5 \mathrm{~cm}$ and with a thickness of $5 \mathrm{~mm}$ was placed in steadystate plasmas of $\mathrm{H}, \mathrm{He}$ and $\mathrm{Ar}$ in the PISCES-A facility. The plasma diameter was set around $6 \mathrm{~cm}$. The magnetic field is perpendicular to the target surface and is 250 Gauss. The typical neutral pressure during plasma operation is $1 \times 10^{-4}$ torr. The plasma bombardment flux, plasma density and electron temperature were measured by a Langmuir probe. Also, an optical spectrometer was aligned in such a way that plasma particle radiations (e.g. H-alpha) could be monitored in-situ, particularly near the specirnen surface. Details of plasma characteristics and materials experiments in this facility can be found in our previous papess. 11,14-16

In order to simulate plasma discharges in existing magnetic fusion devices, the plasma bombardment was conducted for a relatively short period, typically 20-60 seconds although the PISCES-A facility can generate continuous plasmas. The general plasma bombardment conditions during these experiments were: flux in the range from $5 \times 10^{17}$ to $2 \times 10^{18}$ ions $\mathrm{s}^{-1} \mathrm{~cm}^{-2}$; total fluence in the range from $10^{19}$ to $10^{21} \mathrm{ions} / \mathrm{cm}^{2}$ : plasmal bombarding energy in the range from 15 to $300 \mathrm{eV}$; plasma density of the order of $10^{12}$ $\mathrm{cm}^{-3}$; and electron temperature in the range from 5 to $20 \mathrm{eV}$. The temperature of the 
specimen was varied between $15^{\circ} \mathrm{C}$ and 800 eC. More specific experimeanal conditions will be described in each section.

\section{Vacuum characteristics of the PISCES-A facility}

The main vacuum chamber of the PISCES-A facility is pumped by four turbo molecular pumps with the total nominal pumping speed of 6000 liters/s for nitrogen. The effecive total pumping speed after conductance calibration is estimated to be 1700 liters/s by which the base pressure of the order of $10^{6}-10^{-7}$ torr is routinely attained. A residual gas analyzer was used to characterize vacuum conditions in the main chamber before plasma operation. Since the main vacuurn chamber is not bakable, watcr vapor is the predominant residual gas identified the residual gas analyzer. The partial pressures are typically: $\mathrm{P}\left(\mathrm{H}_{2} \mathrm{O}\right): \mathrm{P}\left(\mathrm{H}_{2}\right): \mathrm{P}\left(\mathrm{CO}+\mathrm{N}_{2}\right)=10: 3: 2$.

\section{RESULTS AND DISCUSSION}

\section{A. Plasma Activation of Graphice Surface}

\section{General observations}

In the first series of experiments, the effects of high flutence plasma bombardnent on the gas adsorptivity and on the surface morphology of traphite are investigated. The graphite disk target with a diameter of $10 \mathrm{~cm}$ was lirst bombatrded by continuous be or h plasmas at a flux of $1 \times 10^{18}$ ions $\mathrm{s}^{-1} \mathrm{~cm}^{-2}$ to a fluence of the order of $10^{21} \mathrm{i} \mathrm{w} \mathrm{w} / \mathrm{s} / \mathrm{cm}^{2}$ and at jon bombarding energies between 100 and $200 \mathrm{cV}$. The plastra bonbardment was carricd out under the erosion-dominated condition, which was defincel in our previous work, 15 for physically sputtered carbon atons. During plasma operation, the tolil pressure in the PISCES-facility was typically $1 \times 10^{-4}$ corr and the grathlite comperature was around 800

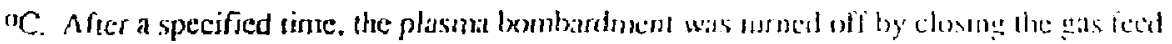

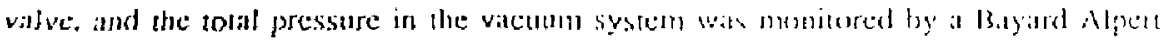

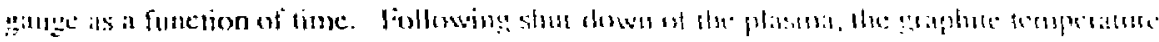
dropped ritpilly wo rom lemperaturs.

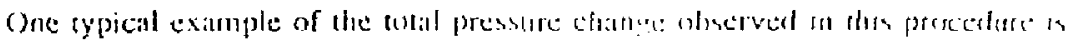

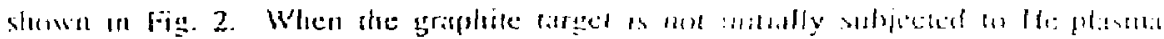


bombirdment, the total pressure rapidly decreitses dowi to tice base pressure of the vacum chamber, which is $=2 \times 10^{-6}$ tors in this parricular case (sec curve-a). However, after Jle-plasma bombardment al an energy of $\mathrm{l}(0) \mathrm{eV}$ for $\mathrm{I0}$ milutes, the toral pressure drops below the initial base pressure and remains there temporarily (sce curve-b). Fusther Heplasma bombardnicnt appears to elongate the duration of she temporary reduction of the total pressure (see curves-c and d). After exposure to He-plasma bombardment for 90 minutes, the total pressure falls to a level about a factor of 2.5 below the base pressure (see curve-e). It can be scen that in this case, the total pressure remains below the base pressure, while gradually increasing. as long as 30 minutes. Also, the total pressure fluctuates for a few minutes, which is referred as 'brearhing' in Fig.2. (The breathing phenomenon will be discussed later, Essentially the same behavior of the total pressure as that described above has been observed in the case when Ar-plasma bombardment at an cnergy of $200 \mathrm{eV}$ is used.

\section{Gelfering specd and capacity of activated graphite}

Observations described above clearly indicate that inert gas plasma bombardment 'activates' the graphite surface, which can then provide an additional pumping speed of about 2500 liters/s. This process immediately reminds us of 'activated charcoal', one of the typical adsorbent materials. ${ }^{17}$ In the reminder of this paper, the inert gas plasma bombardment to attivate the graphite surfice will be referred as the plasma-activation process (PAi). Since the gconetrical plasmit-ficing surface arca of the graphite target is $100 \mathrm{~cm}^{2}$, the initial grencring speed of the activated graphite surface evaluated to be 25 liters $\mathrm{s}^{-1} \mathrm{~cm}^{-2}$, which is equivalent or superior to a typical value of a titanium-gettered surface at liquid nitrogen temperature. 17

The volumetric asrival rate of a molecule, $V_{a}$, can be calculated, using the relarion from the kineric theory of gises: 17

$$
V_{\mathrm{a}}=\sqrt{ }(2 \mathrm{k} \cdot \mathrm{T} / \pi \mathrm{m})
$$

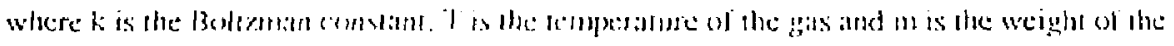

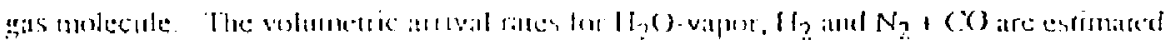

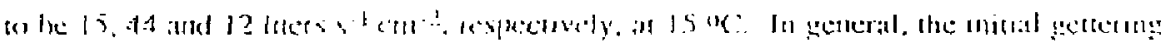

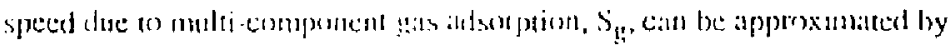




$$
S_{\mathrm{g}}=\sum V_{\mathrm{a}} v
$$

where $v_{a}$ and $v_{\text {are }}$ the volumetric arrival rate and the sticking coefficient of each gas, respectively. Unfrrumbucly, to the best of our knowledge, the sticking coefficients for these residual gases arc not well established for graphite with a strongly plasma-modified surface morphology which will be shown later. It is not possible to obtain the theoretical value of the gettering speed. However, one may conjeclure from a vapor pressure viewpoint that the sticking coefficient for $\mathrm{H}_{2} \mathrm{O}$-vapor far exceeds those of other gases. The initial gettering speed evaluated for the activated graphite surface is thus considered to be within a reasonable range.

The total amount of pumped gas, $Q$, over a certain period can be calculated from the relation: 17

$$
Q=\int q d t
$$

Here, $q$ is the gas throughput given by

$$
q=\mathrm{P}(\mathrm{t}) S_{\mathrm{eff}}
$$

where $\mathrm{P}(\mathrm{t})$ is the pressure as a function of time and $\mathrm{S}_{\mathrm{cff}}$ is the effective pumping speed of the vacuum system. From the curve-e shown in Fig.2, the total gas getrering capacity of the activated gettering surface is estimated to be 0.025 tor-liter $/ \mathrm{cm}^{2}$ (i.e. $8.3 \times 10^{17}$ molecules/cm ${ }^{2}$ ). It is important to note here that the graphite surfacc, once saturated, can be reactivated for gettering by incre gals plasma bombardnent to a relatively iow flucnce. Assuming monolayer adsorption on graphite with a nominal surface density of $2.4 \times 10^{15}$ atoms $/ \mathrm{cm}^{2}$, the estimated gettering capacity lcads to at surface roughness factor of 345 . This crude estimate of the roughiness factor is not significanty differem from reported values. 13

\section{Surface modificasion aswotiated with plasma activafion}

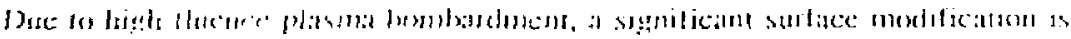

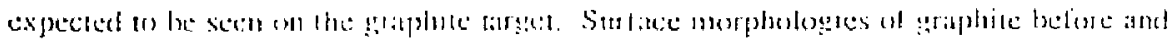

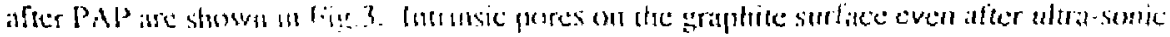

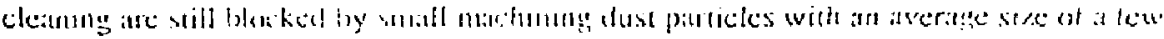


microns (see pieture-a). After PAP, the pore opening is significantly increased and the surface appears to be rather smontis (see pictures-b and $c$ ). The observed increalse in pore opening is obviously due 10 surface modification via physical sputtering. In fact, He. plasma bombardment conditions during PAP lead 10 an erosion rate of typically 6.5 $\mu \mathrm{m} /$ hour. This mates it possible to completely erode the dust particles blocking the pores. For these sponge-like surface morphologies, the large roughness factor evaluated in section III-A-2 is not surprising.

\section{Possible mechanisms for gettering by activated graphite}

Gettering by activated graphite may be explained by the following mechanisms:

(1) High flux inert gas plasma bombardment at elevated temperatures induces significant thermal and kinemarical desorption of previously dissolved and adsorbed impurities from graphite. As a result, the surface adsorption sites will be unoccupied. Moreover, an sppreciable number of radiation damages, which are likely to have unsaturated valences, will be generated on the surface during PAP. Therefore, the plasma-activated graphite surface is expecred to have an increased gas adsorptivity. (2) More importandy, one can expect enhancement of the gas retention capability from the capillary effect 17 due to the sponge-like surface morphology (see Fig. 3). Is follows that the gettering speed depends on the degree of surface pore opening. This is quite consistent with the observed fact that the gettering period whs prolonged by increasing He-plasma bombardment fluence (see Fig. 2). Also, open porcs on the surfice will provide a better conductance for molecular llow into pores, which also contributes to the large initial gettering speed. (3) As mentioned earlier, the yeical plasmi bombardment flux (of the order of $10^{18}$ jons s-1 $\mathrm{car}^{-2}$ ) during PAP is appreciably higher than the total arrival rate of residual gases (of the order of $10^{15}$ molecules $\mathrm{s}^{-1} \mathrm{em}^{-2}$ at solil pressures around $10^{-6}$ torr). Therefore, high flux inere gas plasnia bombardment will prevent the atcrivated surfice sites from being adsorbed with residual gases. After PAP, the adsorptive surface is exposed to residual gases and will then exhibit the gettertins effect

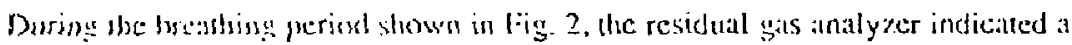

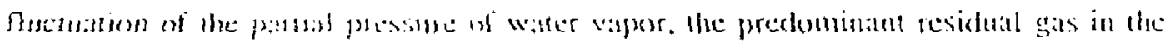

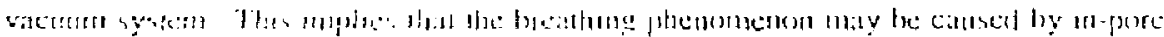

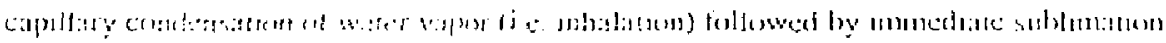

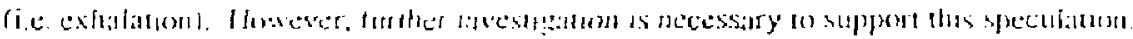


The graphite target is croded via physical sputtering during PAP. Conserfuchtly. spultered carbon will be deposited on the chamber wall at room icmperature. Ont unestion which can be raised hese is whether or not the deposited carbon on the vilcul $r$. hamber wall coneributes to the observed gettering effect. The answer is negative for the lollowing reasons: (1) The geometrical surface area of the vacuum wall to be deposited with sputtered carbon is about two orders of magnitude larger than that of the graphite target. It follows that the carbon deposit is not thick enough to provide capillary effects. (2) It is true that the carbon deposition can provide a fresh surface on the vacuum wall at an average rate of the order of $10^{14}$ atoms $\mathrm{s}^{-1} \mathrm{~cm}^{-2}$. However, the carbon-deposited wall is constantly exposed to residual gas molecules during PAP. The total arrival rate of residual molecules is of the order of $10^{15}$ molecules $\mathrm{s}^{-1} \mathrm{~cm}^{-2}$ at total pressures around $10^{-6}$ torr. Ualike the graphite target, the carbon-de josited wall is not bombarded with the inert gas plasma during PAP. These arguments indicate that the carbon-deposited wall surface is saturated with adsorbed gases before PAP is finished. (3) Generally, carbon is not considered to retain its volatile compounds such as oxide (e.g. $\mathrm{CO}$ ) and hydride (e.g. $\mathrm{CH}_{4}$ ) on its surface at room temperature without capillary effect.

For completeness of investigntion, plasma activation of graphite was antempred using $\mathrm{H}$-plasma bombardment at an energy of $100 \mathrm{eV}$. However, no gettering effect was observed. This can be explained as collows. High flux, high fluence H-plasma bembardment induces surface radiation damages, physical sputtering and then provides a sponge-like surface morphology to graphite. 11 However, it is also true that H-plasma bomberdnent causes chemical sputtering of grophite. Due to chemical sputtering, active radiation damage sites will be likely consumed to produce hydrocarbons (e.g. $\mathrm{CH}_{4}$ ). Also, refreshed surface adsorption sites, if exist, will be immediately occupied by reactive alomic byorogen. Hence, when the H-plasma bombardment is frnished, there is ro komger enough surface gas-adsorpivity to provide observable gettering effects in the PISCES-A fituility.

It should be emplasized here again that gettering by activated graphite is govened by physical adsorption of molecules on the stiface. It follows that the getuering tfect strongly depends on vacuum characteristics of the system. The fact that line base pressure of the PISCES-A facility is of the order of $10^{-6}-10^{-7}$ torr broughe ahout the present findings. In inother word, it is probably difficult to observe the bettering ellect in will-

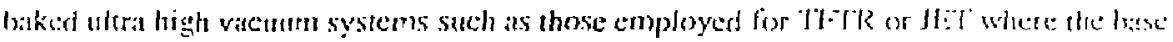

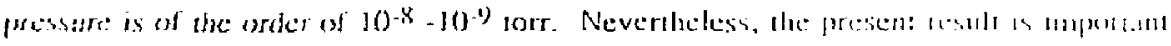

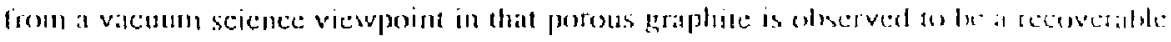
gester in highl vicum systems. 


\section{B. Hydrogen Recycling under Plasma Bombardment}

The obsermions described in section !JI-A has lesi to a hypothests that the geturing graphice surface will somehow retain is hydrogen plasma particle influx until it saturates and that this effect will be reflected in hydrogen recycling behavior. To verify the hypothesis, the graphite target was bombardad by H-plasmas with fluxes between $5 \times 10^{17}$ and $2 \times 10^{18}$ ions $\mathrm{s}^{-1} \mathrm{~cm}^{-2}$. The H-plasma bombarding energy was set at $300 \mathrm{eV}$. These condicions are believed to be relevant to the plasma-surface interactions in tokamaks such as TFTR.8.18 Hydrogen recycling benavior was measured with $\mathrm{H}$-alpha speciroscopy calibrated in the manner to be described in the next section. The exposure time to H-plasma bombardment for recycling measurements was timited of a relativeij short period of 20 seconds to sissujaic discharge conditions in existing magnetic fusion devices. The plasma in the PISCES-A facility reproducibly reaches the steady state condition within at short timc consant (0.1-0.2 second), compared with the chararteristic recycling time constant to be discussed iater.

\section{H-alpha spectroscopy for hyarogen meycling measurements}

To review britfly, the important atomic phy ics processes associated with hydrogen recycling from a material sur:açe under H-plasma bombardment include:

(1) dissociation reactions of reemitted wolecular hydrogen (e.g. $\mathrm{H}_{2}+\mathrm{e}^{-}=>\mathrm{H}+\mathrm{H}+\mathrm{e}^{-}$);

(2) excitation reactions of atomic hydroge $\rightarrow$ (e.g, $\mathrm{H}+\mathrm{e}^{*}=>\mathrm{H}^{*}$ );

(3) rclaxation rea. ions of excited acomic hydrogen (e.g. $H^{*} \Rightarrow 11+$ lwv);

(4) ionization reactions of abmic hydrogen (c.s. $\mathrm{H}+\mathrm{c}^{-}=>\mathrm{H}^{+}+2 \mathrm{c}^{-}$).

As a whole, one cari understand the significance of these consecutive processes as follows. Reemit:ed hydrogen nolecules with thermat energies will be most likely dissociated very near the surface. Consequently, the mitjor component in the locial recycling region is atomte hydrogen, thrs cxcited neutral of which emits $H$-alpha light. In ine present work, the brightness of H-alpha ratiation is approximned as an indirect meastere of the density of

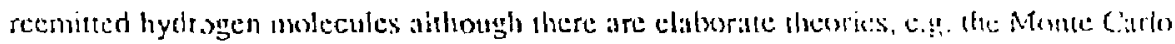

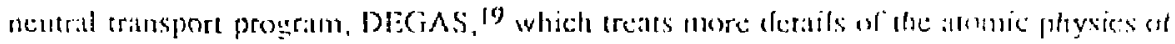
hydrom recedims.

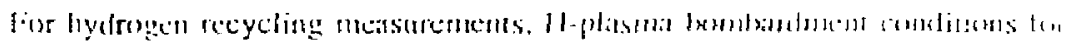

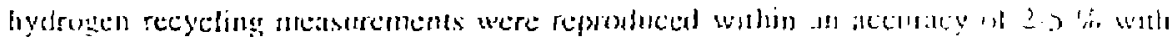


respect to plasma density and electron temperature. Within the accuracy of reproducibility, if necessary, the H-alpha brightness was corrected using the following relation: 20

$$
B \propto n_{H} n_{c}<\sigma y>
$$

where $B$ is the brightness of $\mathrm{H}-a$ alpha, $n_{H}$ is the neutral atomic hydrogen density, $n_{e}$ is the electron density, and <ov> is the rate coefficient for the reaction: $\mathrm{H}+e^{-} \Rightarrow \mathrm{H}^{+}+2 \mathrm{e}^{-}$which is a function of electron temperature. Therefore, the corrected $\mathrm{H}$-alpha brightness can be used as a semi-quantitative measure to represent hydrogen recycling behavior.

\section{Aydrogen recyciing at low temperalures}

First, the graphite surface was activated by He-plasma bombardment in the manner described in section III-A-1. Immediatcly after PAP, H-plasma bombardment was initiated for hydrogen recycling measurement so that the activated graphite surface would not significantly getter residual gases in the vacuum system. The H-plasma bombardment was then continued 5 minutes to ensure surface saturation with hydrogen. The pre-saturated surface was again subjected to H-plasma bombardment for hydrogen recycling measurement.

In this experiment, the net $H$-plasma bombardment influx was set at $t \times 10^{18}$ ions $\mathrm{s}^{-1} \mathrm{~cm}^{-2}$, corrected by the kinematical particle reflection coefficient of 0.15 from the $\mathrm{TR} / \mathrm{M}$ $\operatorname{code}^{21}$ The plasma density and electron temperature were $5.7 \times 10^{11} \mathrm{~cm}^{-3}$ and $20 \mathrm{cV}$, respectively. Under these conditions, the graphize surface is roughly tstimaled 60 be eroded by $5400 \dot{A}$ after 5 minutes. This means that the surface layer implanted and damaged with energeric helium ions during the initial PAP was completely renoved befiole hydrogen recycling measurement was resumed.

Typical behavior of hydrogen recycling from the activated and pre-saturated graphite surfaces is shown in Fig.4. Notice that hydrogen recmission from the activated surface is significantly retarded, relative to that from the pre-saturated surface, in the time to approach ' ie steady state (100\% reemission). This clearly shows that the activilled sulfice can 'pump' H-plasma particle:. The piasma pumping capability call be sisily recosedel.

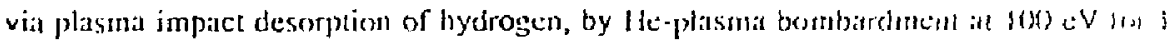

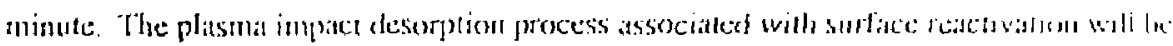
described later in denal. 
Because of the significant heal thux due to the ll-plasma bombardment $\approx 55$ $W / \mathrm{cm}^{2}$ ), the temperaturs of the sraphite target on at water-cooled holder rises to 100 "C towards the end of the plasina exposure time. IJowever, the rise of emperature is not 50 drastic as to cause significant excess recmission. 22 Rather, it is important to point out here that the temperature of the activated surface under H-plasma bombardment is gencraily lower than that of the pre-saturated surface. The temperaturc measurenent is done using a thermocouple attached to the specimen surface that is not exposed to the hydrogen plasma. Thus, the measured temperature is not directly selated to the surface phenomena. Yet the observation described above is indicative of several possibilities: a reduced thermal conductivity from the activated surface to the bulk and/or some endothermic effect associated with hydrogen implantation.

\section{Kinetic considerations of hydrogen recycling}

Hydrogen recycling measurements havi: conventionally been conducted using ion beam facilities which are typically capable of producing hydrogen ion fluxes of the order of $10^{15}$ ions $\mathrm{s}^{-1} \mathrm{~cm}^{-2}$. It is observed in these ion beam experiments that unlike metallic materials, hydrogen reemission from graphite does not apparently initiate until the surface layer is saturated with implanted hydrogen to the implantation depth. The saturation concentration is normally 0.4 in terms of the $H / C$ atomic ratio 23 and does not seem to depend strongly upon the implantation energy. The hydrogen saturation capacity is generally attributed to trapping sites existing in the graphite structure. However, one should always bare in mind that there is 1 hidden uncertainty as large as $50-100 \%$ in the reported data because nominal propertics of isotropic graphite materials are far more 'statistical' 23 than those of metals and alloys.

After surface saturation, hydrogen recunission from graphite rapidly approaches the steady state. Therefore, one may consicter ihat the tolal hydrogen concentration at dice steady state is not significantly different from the initial saturation concentration. In parallel, hydrogen accumulation (i.e. retemtion) proceeds in sucl a way that a limited

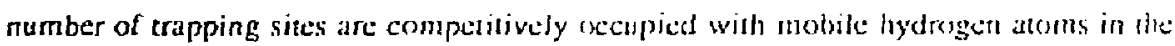
implantation range, as described by the 1 , real Nixing Mextet 25 These chatracteristics of

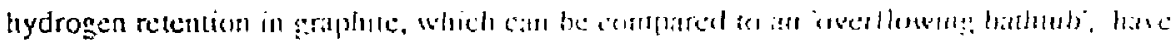

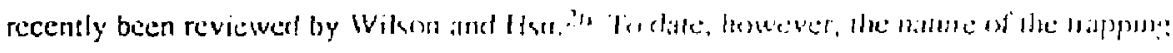

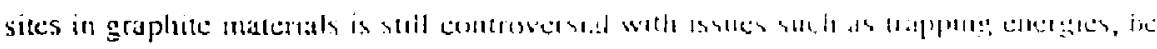

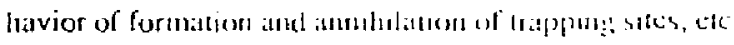


In the present experiments, the typical H-plasma bombardment flux is about $\hat{j}$ orders of inagnitude higher than the ordinary ion bean nux. This means that a 'bathtub' is expected to overflow soon after H-plasma bombardment starts in the PISCES-A facility. In fact, virtually no incubation period associated with the surface saturation is seen in the observed hydrogen reemission behavior shown in Fig. 4.

The hydrogen transport theory developed by Doyle 27 is applied here to determine the rate-limiting step in hydrogen reemission. From the theory, one can use the relation:

$$
W_{0}=\left(R_{d} / D\right) \sqrt{ }\left(K_{d} / J_{0}\right)
$$

where $W_{0}$ is the dimensionless transport parameter for the upstream surface, $R_{d}$ is the implantation depth, $L$ is the thickness of the target, $D$ is the hydrogen diffusivity, $K_{o}$ is the recombination constant, and $\mathrm{J}_{0}$ the net incoming hydrogen flux corrected by the kinematical particle reflection coefficient. The dimensionless parameter, $W_{0}$, is calculated to be above unity, using reported values 28 for the constituent parameters and $R_{d}$ calculated from the TRIM code. In this case, hydrogen reemission kinetics is categorized in the DD-regime (diffusion-limited) under the present experimental conditions. From the same theory, 27 the recycle time is defined by the relation:

$$
\left.\tau_{1 / 2}=R_{d}{ }^{2} / 0 \text { (for } W_{0}>1\right)
$$

The calculated recycle time is $5 \times 10^{-2} \mathrm{~s}$, too short to interpret the data shown in Fig. 4.

Based on the result from the dimensionless parameter analysis, the DIFFUSE code 29 was executed with a Sieverts' law boundary condition to simulate the hydrogen recycling behavior. The parameters for Sieverts' constant are tabulated elsewhere. 28 For this calculation, the hydrogen implantation profite is computed using the TRISt code (sec Fig.6). The trapping site concentration (in terms of the $n_{t r a p} / n_{\text {carbon }}$ ratio, where $n$ is the density) is set at 0.4 over the implantation depth. The hydrogen trapping energy is assumed to be $2.5 \mathrm{ev} .23$ For simplicity, the rise of the temperature is approximated by a linear ramp from 15 to $95^{\circ} \mathrm{C}$ at a constant rate of 4 degres/s. In igig.5, the computed hydrogen recyeling behavior with the DIFFUSE code is compared will the experimental data for the activased graptrite. The calculated hydrogen recmissins sbens considerably rapici rise to

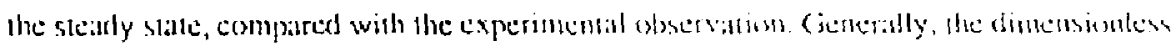

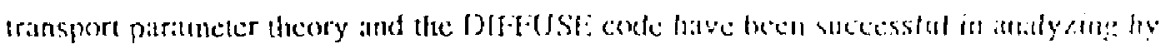

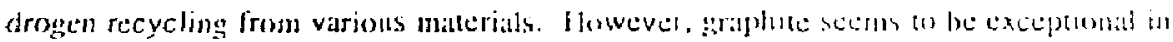


this regard. This is probably duc to the complicated surface characteristics of the graphite matcrial used in this work.

As a fitting procedure to evaluate the characteristic time constant, the observed recmission curve is approximated by an exponential increase followed by a saturation in the manner:

$$
I_{r}(t)=I_{o}\{1-\exp (-u \tau)\}
$$

where $\mathrm{J}_{r}$ and $\mathrm{J}_{0}$ are the reemitting and net incoming fluxes of hydrogen, respectively, and $\tau$ is the characteristic time constant. The calculated reemission curves from eq.(7) are superimposed on the experimental data points shown in Figs 4 and 5 . The fitted time constants for hydrogen reemission from the activated and pre-saturated surfaces are 1.7 and $0.8 \mathrm{~s}$, respectively.

Similarly, the following relation defines the 'dynamic' retention of hydrogen, $C_{\tau}$. during H-plasma bombardment:

$$
C_{r}(t) \equiv\left\{\left(J_{O^{-}} J_{r}\right) d t=\tau J_{0}[1-\exp (-t / \tau)\}\right.
$$

The 'dynamic' retention is the total non-reemitted hydrogen fluence including hydrogen trapped in graphite and hyćrogen lost due to surface erosion. The final dynamic retention of hydrogen, given as $C_{r}(\infty)$, is calculated to be $1.7 \times 10^{18}$ ionsicm ${ }^{2}$ and $7.9 \times 10^{17}$ ions $/ \mathrm{cm}^{2}$ for the activited and pre-saturated surfaces, respectively. Considering the typical composition of hydrogen plasma species in the PISCES-A facitity: ${ }^{11} 75 \% \mathrm{H}^{+}, 20 \% \mathrm{H}_{2}{ }^{+}$ and $109 \mathrm{H}_{3}{ }^{+}$, the hydrogen retention values above correspond to $2 \times 10^{18} \mathrm{H} / \mathrm{cm}^{2}$ and 9.5 $\left.\times 10^{17} \mathrm{H} / \mathrm{cm}\right)^{2}$, respectively.

\section{Possible mechanisms for high hydrogen recendion}

High hydrogen retention data for graphite moterials have been recently reported. 30,31 Using it stow discharge lechaque, I,angley 30 obtained a hydrogen

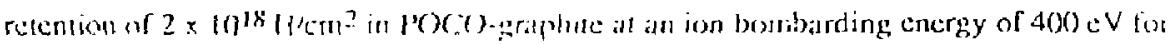

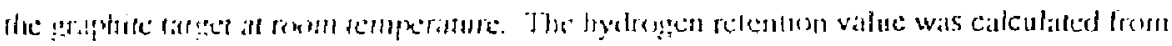

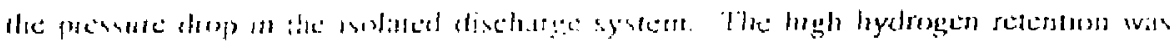

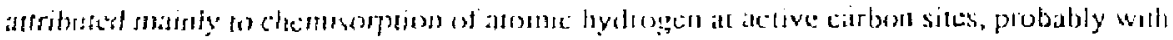

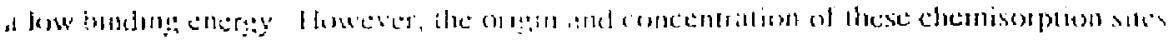


were not well defined or correlated with the observations. Ifsu and Causcy ${ }^{31}$ observed int apparently high hydrogen retention of $1.1 \times 1019 \mathrm{D} / \mathrm{cm}^{2}$, using a Penning discharge system with graphite cathodes, al implantation voltages between 300 and $500 \mathrm{ev}$. This high retention value ivas, however, found to be duc to formation of a hydrogen-ricl $(7.2 \times 1017$ D $/ \mathrm{cm}^{2}$ ) carbonaceous film, via co-deposition, on the discharge vessel wall components. The nature of the co-deposited fint might be similar to that of the carbonized wall in TEXTOR ${ }^{4}$ although details are still unclear. These arguments are not directly applicable to the present experiments nor do they appear to explain the present findings. Therefore, several possible mechanisms are proposed here.

The activated surface is found here to have about a factor of two larger dynamic retention of hydrogen than the pre-saturated surface. The net effect of He-plasma activation. i.e. the difference in the dynamic hydrogen ratention for activated and pre-saturated surfaces, appears to be equivalent to the gettering capacity of the activated surface. This Jeads to a conjecture that the extra hydrogen might reside at aclivated surface adsorplion sites, both on the 'flat' and in-pore surfaces, perhaps ir. the form of surface radicals such as $\mathrm{C}-\mathrm{H}$ and $\mathrm{H}-\mathrm{C}-\mathrm{H}$ although details of the surface chemistry are still unknown. Recenily. Causey et.al. 32 have also found out that at temperatures below $=130 \circ \mathrm{C}$, surface chemisortion sites in the internal pores can increase the effective retention of deuterium and tricium implanted at an energy of $100 \mathrm{eV}$ to the level significantly excerding the one that the bathtub concept predicts.

One may apply the bathtub concept to a highly porous surface. The existing hydrogen saturation concentration data are mostly taken from isotropic graphite materials, pores of which may not be fully opened to the surface. It is not easy to determine whether the BET surface area of an isotropic graphite material increases due to removal of dust particles along with high fluence plasma bombardment. However, increasing open pores on the graphite surface will certainly iscrease the effective plasma-facing surface area. II follows that the sponge-like surface morphology, shown in Fig. 3, can topographically increase the effective lydrogen retcration capacity is terms of $H / \mathrm{cm}^{2}$. Unfortunalely, the surface roughness factor evilutled liere does not guantitatively suppon this argument.

As observed for stainkess sceel, ${ }^{33}$ pre-damage sites due to He-plasma bombardnien associated with PAI' anight lead to an incteiste in the number of internal trappong sites lan

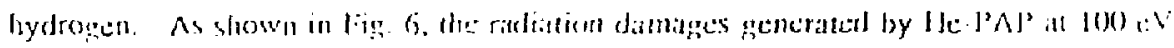

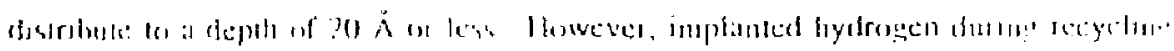

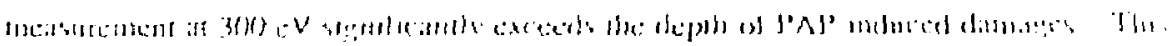

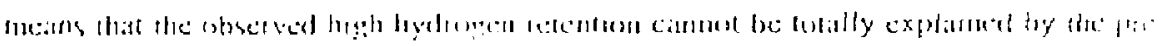

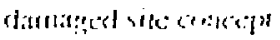




\section{Dynamic hydrogen recention by pre-saturated graphite}

It is important to point out here that the pre-saturated surface also appears to pump $H$-plasma particles to a significant amount. This effect has been found to be reproduciblt. meaning that the surface is virtually non-saturable with hydrogen. The definition of the 'pre-saturated' surface is not consistent with this finding. Therefore, one should attribute the observed plasma pumping by the pre-saturated surface to a dynamic hydrogen retention capability. From the sponge-like surface morphology, a transient pumping mechanism is conjectured here that hydrogen might be stored temporally in pores under plasma bombardment and then be released later on. This will cause a particle imbalance between the fast implantation and slow release of hydrogen during plasma bombardment.

serally, behavior of gas release from a surface can be influenced by stagnation of released gas. This is particularly true when the gas-surface system is not well ventilated. Thus, the slow release of hydrogen in this case is probably due to the namow, deep pore channels. This may be one of reasons for the fact that the kinetic analysis of the present data using the DIFFUSE code has been unsuccessful.

This transient plasma pumping behavior is phesomenologically similar to that observed in JET 7 in that the graphite surface can reproducibly pump H-plasmas without He-plasma discharge conditioning. In $\mathrm{JET}$, the delayed hydrogen reemission peak is observed with $H$-alpha spectroscopy when the $H$-plasma is moved from lhe inuer graphice wall. However, this delayed H-alpha peak observed in JET has not been clearly atuributed to a surface structural effect. In order to experimentally verify the trinsicnt pumpun: mechanism conjectured here. we attempted to observe the delayed remission of hyedro!from the pre-saturated graphite surface, using a residual gas analyzcr, immediately d! ier IIplasma bombardment. Because the hydrogen partial pressure is high (typically. $1 \times 10^{\text {s }}$ torr) during plasma operation in the PISCES-facility, no clear evidence of the delayed recmission of hydrogen was obtained. However, a delayed emission of $\mathrm{Cll}_{4}$ was observed in such a way that the intensity of $\mathrm{CH}_{4}$ signal peaks before it fades out (slower schematically in lig. 9). "This is indicative of transient storage of molecules withe pursts Infortunately, no fureler experimental sviftence is available wa datc. 


\section{Effect of reactivation procedure on hydrogen recycling}

The activated surface, once siturated, can be reactivated by lle-plasmil bombardment at as energy of $100 \mathrm{cV}$. During reactivation, graphite is subject to surface erosion at a physical sputtcring yield of $3 \times 10^{-2}$ atoms/ion. ${ }^{34}$ The graphite surface is eroded by $1600 \dot{A}$ after exposure to He-plasma bombardment at a llux of $1 \times 10^{18}$ ions $5^{-1}$ $\mathrm{cm}^{-2}$ for 1 minute. As shown in Fig. 6, the implantation depth of hydrogen at $300 \mathrm{eV}$ in graphite is $150 \AA$ or less. These calculations indicate that pre-implanted hydrogen will be completely removed along with carbon erosion during reactivation. As a result, graphite is given a fresh activated surface.

One question here is whether or not the graphite surface can be reactivated even if He-plasma bombardment is not ene etic enough to remove pre-implanted hydrogen completely. To investigate this possibility, a pre-saturated graphite surface was bombisded by a He-plasma at $15 \mathrm{eV}$, an energy below the theoretical physical sputtering threshold for carbon ( $=28.5 \mathrm{eV}{ }^{34}$ ). Subsequent hydrogen recycling measurements indicated that the graphite surface is reactivated even by non-sputtering He-plasma bombardment. In fact, the characteristic time constant for hydrogen recycling is evaluated to be $1.8 \mathrm{~s}$, which is essentially the same as that of graphite reactivated by He-plasma bombardment at $100 \mathrm{eV}$. The pre-saturated graphite surface was also bombarded by Ar-plasmas at 50 and $100 \mathrm{eV}$, energies below the theorctical physical sputtering threshold for carbon $\left(=112.7 \mathrm{eV}{ }^{34}\right.$ ). The resultant graphite surfaces clearly exhibited plasma pumping capabilities. The important implication of these non-sputtering reactivation processes will be diescribed later in detail.

\section{Effect of air-exposure of activated graphite on hydrogen recycling}

In this scction, the effect of air-exposure of an activated surface on hydregen recy cling behavior is discussed. The graphite targec was first activated and immedialtsy exposed to the air for $5 \mathrm{~min}$. The air-exposed surface was then sutjected to 11 -plivithat bombardment ior recyching meisurement. The plasma bombardnent tlux in llus

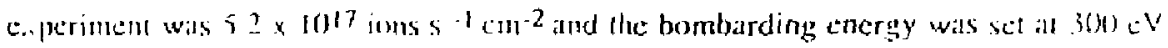

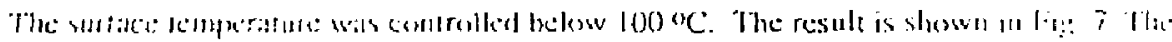

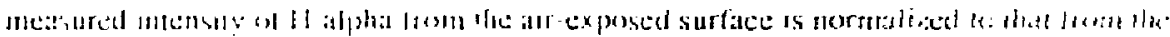

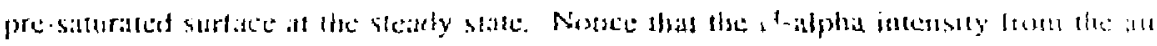

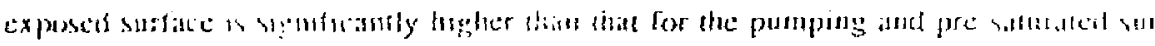


faces. This is obviously duc to adsorption of molccules, e.g. $\mathrm{H}_{2} \mathrm{O}$, during air exjosure. It follows from this that the activated surface is very air-sensitive, consistent with the gettering nature described in section $111-A$.

The $\mathbf{H}$-ajpha intensity, once increased if fter air-exposure, gradually decreased and reached the level similar to that for the pre-saturated surface afier extensive II-plasma bombardment to a nuence of the order of $10^{21}$ ions $/ \mathrm{cm}^{2}$. This reminds us of tokamak wall conditioning using hundreds of hydrogen plasma discharges. As shown in Fig. 7, the airexposed surface was found to be reactivated by He-plasma bombardment at an energy of $100 \mathrm{eV}$ for only 1 minute, corresponding to a fluence of $6 \times 10^{19} \mathrm{jons} / \mathrm{cm}^{2}$. It follows directly from these findings that PAP will be quite useful in conditioning graphite surface components in a large toroidal fusion device, particularly after vacuum openings.

The dynamic hydrogen retention estimated in this case is $1.9 \times 10^{18}$ and $6.2 \times 10^{17}$ $\mathrm{H} / \mathrm{cm}^{2}$ for the activaled and pre-saturated surfaces, respectively. These well agree with the corresponding values obtained when the $H$-plasma bombardment $7 u x$ is set at $1 \times 10^{18}$ ions $\mathrm{s}^{-1} \mathrm{~cm}^{-2}$. This indicates that the activated and pre-saturated surface have respective constant plasma-pumping capacities, regardless of plasma bombardment flux. Therefore, it can be expected that if the plasma paricle load is smaller, a activated graphite limiter will provide reduced local recycling for more confinement discharges.

\section{Hydrogen recycling at elevated temperatures}

To investigate indrogen reemission hehavior when surface recombitation plays an important role (i.e. in the RD-regime for $w_{0}$ " 127 ), the graphite teimperature was

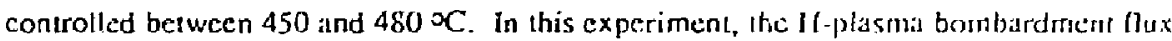
and energy were $6 \times 10^{17}$ ions $\mathrm{s}^{-1} \mathrm{~cm}^{-2}$ and $300 \mathrm{eV}$, respectively. The result is shown in Fig. 8. Again, hydrogen recmission from the activated surface is reljrded, relative to that from the pre-saturated surface. However, no steady state recrission is atained within :J specif:ed plasma exposure time. Only a short transient plateau is observed for the presaturated surface, around 3-4 stconds after fl-plasma boinbardinenl starts. Fot

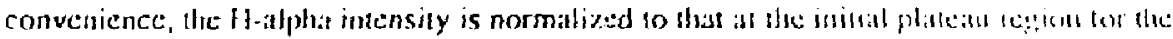

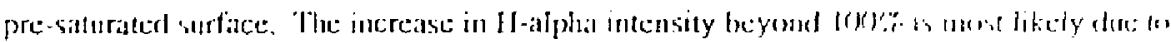

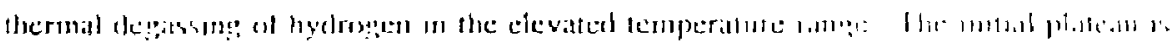

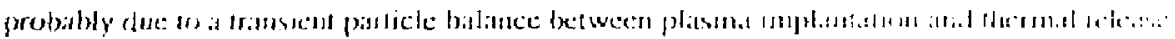

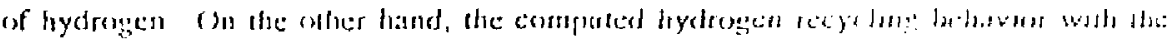

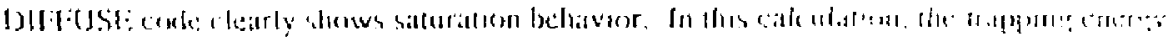


is assumed to be $2.5 \mathrm{eV}$. Ihese results suggest that there might be other trapping sites with lower binding energics which lead to a themal desorpeion al lower emperatures. Further experiments at elevated temperatures are under way.

Because of the non-saturation nature, eq.(7) cannot be applied to estimate the dynamic hydrogen retention. Instead, the dynamic hydrogen retention to the initial plateau level is graphically evaluated to be $7.9 \times 10^{17}$ and $2.7 \times 10^{17} \mathrm{H} / \mathrm{cm}^{2}$ for the activated and pre-saturated surfaces, respectively. The dynamic hydrogen retention is appreciably reduced, relative to that estimated at temperatures below $100{ }^{\circ} \mathrm{C}$. However, this is not surprising since the surface adsorptivity is generally lower at elevated temperatures. Also, it is wel: known that hydrogen trapping sites are largely (70-80\%) disabled at temperatures around 500 \%C.26 Nevertheless, the dynamic hydrogen retention cvaluated here is still significantly larger than that one would expect from the bathtub concept based on the temperature dependent hydrogen trapping capacity.

\section{Hydrocarbon Formation during Hydrogen Recycling}

As can be seen in earlier sections, $\mathrm{H}$-alpha spectroscopy measurements provide the key information to analyze hydrogen recycling behavior. For a given amount of incoming $H$-plasma flux, however, the brigheness of $H$-alpha radiation may be reduced due to chemical sputtering of the graphite surface since hydrogen is consumed for hydrocarbon formation as well is reemission. In this section, the behavios of clatmical sputtering of an activated graphite surface and its effect on $\mathrm{H}$-atpha measurements are brieny discussed.

For this purpose, the intensity of $\mathrm{CH}_{4}$ radiation band at at wave lenglh of $5430 \AA$ was monitored during $H$-plasma bombardment. The fi-plasma bonbardntem was carricd out at a flux of $5 \times 10^{17}$ ions $\mathrm{s}^{-1} \mathrm{~cm}^{-2}$ at an energy of $300 \mathrm{eV}$. The surface kemperature was controlled below $100^{\circ} \mathrm{C}$. (These conditions are essentially the same as those used for hydrogen recycling measurements described in section I11-B-6.) A typical result is shown in Fig. 9. The intensity of $\mathrm{CH}_{4}$ radiation band shows an exponential increase followed by a steady state, time dependent behavior similar to bydrogen recmission. This clearly itt-

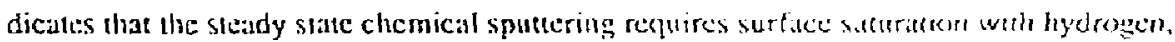

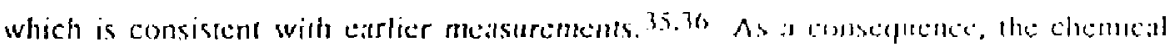

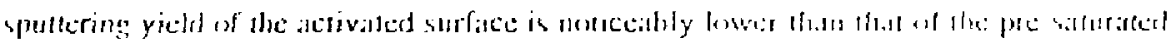

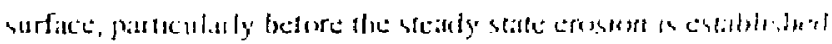

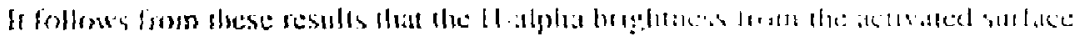

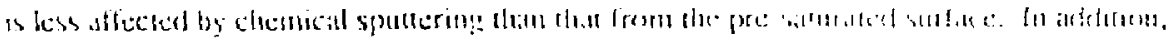


no significant hydrocarbon formation is expected from chemical sputtering at temperitures bclow $100^{\circ} \mathrm{C}$. There are some atomic plyysics processes to decompose hydrocarbons into atomic hydrogen, which then emits $H$-alpha light. This effect can virtually increatse the intensily of H-alpha brightness. However, these processes are not likely to occur near the graphice surface for the plasma densitics and electron temperatures generated in the PISCES-A facility. Details of atomic physics processes including hydrocarbons can be found elsewhere. ${ }^{37}$ As a whole, there is no significent effect due to chemical sputtering on H-alpha measurements.

\section{Hydrogen Release by Plasma Impact Desorption}

In many fusion devices, plasma discharge cleaning has been used for conditioning plasma-facing components so as to minimize impurity emission during confinement experiments. In this regard, it is : nportant to understand the mechanism of particle release from the surface under plasma bombardment. To date, considerable effort has been made to establish a data base, particularly for ion impact desorption cross sections. ${ }^{38}$ These theasurements have never been conducted using high flux plasmas. in the present work, iner gas plasma bombardment has been found to remove saturated hydrogen and reactivate the graphite surface. It is of grcat interest to investigate behavior of hydrogen release along with the reactivation process. It is also true that if inert gas plasma bombardment is used for wall conditioning in fusion devices, thest inert gases will be released and bchave as impuritics in the subsequent $\mathrm{H}$-plasma discharges. For these reasons, plasma impact desorption of hyorogen, helium and argon is discissed in delail in this section.

\section{Masic ihcorctical considerations}

To describe the plasma impact desorption process, the recycling effect on the net iemovil rate must be considered unlike the ordinary ion impact desorption process. [.et " he denoled as the number al particles retained on the sulfuce. The following deserption rate expunikn is oblatinced:

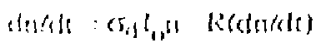


where $\sigma_{d}$ is the cross section for plasma impact desorption, $J_{0}$ is the plasma flux, $t$ is the time and $R$ is the particle recycling coefficient. The solution of eq.(9) is expressed as

$$
\ln \left\{\left(n-n_{\infty}\right) /\left(n_{0}-n_{\infty}\right)\right\}=-\sigma_{d^{*}} J t
$$

where $n_{0}$ and $n_{\infty}$ are the values of $n$ at $t=0$ and $t=\infty$, respectively, and

$$
\sigma_{d}^{*} \equiv \sigma_{d} /(1-R)
$$

Here, $\sigma_{d}{ }^{*}$ is defined as the 'effective' cross section for plasma impact desorption. At the early stages of plasma impact desorption where $n_{\infty} \approx n$ and $n_{\infty}$ \& $n_{0}$, the solution of eq.(10a) can be simplified to the form:

$$
\ln \left(\mathbf{n} / \mathbf{n}_{\mathbf{0}}\right)=-\sigma_{\mathbf{d}^{*}} \mathrm{It}
$$

The particle recycling coefficient, $R$, in the PISCES-A facility is equivalent to the probability of redeposition defined in our previous work. 15 This means that $R$ is a function of the mean free path for electron impact ionization of the particle released from the surface. Generally, the mean free path for electron impact ionization, $\lambda$, can be calculated from the relation:

$$
\lambda=v_{3 v} /\left(n_{\varsigma}<\sigma v>\right)
$$

where $V_{3 v}$ is the averaged velocity over the cnergy distribution of the desorbing particles. $\mathbf{n}_{e}$ is the plasma density and $<\sigma v>$ is the rate cocfficient for electron impact ionization. Assuming a planer surface petential, the energy distribution necded to determinc $v_{\text {av }}$ is given by the iclation:

$$
N(E)=E\left(E+E_{b}\right)^{3}
$$

where $E$ is the energy and $t_{b}$ is the binding energy of the elemente the surfiee. 


\section{Experimental observations of plasma-impact desorption}

The effective plasma impact desorption cross sections have becil measured in the foltowing cases: (1) H-desorption by He-plasma bombardment; (2) H-desorption by Arplasma bombardment; (3) He-desorption by H-plasma bombardment; and (4) Ardesorption by $\mathrm{H}$-piasma bornbardment. For cases; (1) and (2), pre-saturated graphite was used after $\mathrm{H}$-plasma bombardment at an energy of $300 \mathrm{eV}$. Helium and argon preimplantation for cases; (3) and (4) was conducted at an energy of $100 \mathrm{eV}$ to a fluence of $3 x$ $10^{20} \mathrm{ion} \$ / \mathrm{cm}^{2}$. Plasma bombardment for desorption measurements was done at a flux of $\approx$ $1 \times 10^{18}$ ions s-1 $\mathrm{cm}^{-2}$ at energies between 15 and $300 \mathrm{eV}$. Plasma parameters were controlled such that the recycling coefficient described in the previous section can be minimized. Thus, little recycling and redeposition occur. The graphite target temperature was held below $60^{\circ} \mathrm{C}$ so as to avoid any significant thermal outgassing during plastraimpact desorption. The plasma-impact desorption process was monitored in-situ by spectroscopic measurements of $\mathrm{H}$-alpha, $\mathrm{He}-\mathrm{I}$ and Ar-l radiation litues at a wave length of $6562.8,3888.6$ and $6965 \dot{A}$, respectively. The spectroscopic technique used here is based on the relation:

$$
\ln \left(U / I_{0}\right)=\ln \left(n / n_{0}\right)=-\sigma_{d}^{*} J t
$$

where $I$ and $I_{0}$ are the intensity of the radiation line of interest at $t=t$ and $t=0$, respectively.

Unfortunately, there is no established data base for the binding energies of $\mathrm{H}$, He and $A r$ to the graphite surface or bulk. A best guess is that $E_{b}$ may be a few electron voits. To determine a benchinark value (possible maximum) of $R$ in eq.(10-b). let us assume $A r$ to be released from graphite with $\mathrm{E}_{b}=2 \mathrm{eV}$ under He-plasma bombardment with $n_{e}=2 x$ $10^{12} \mathrm{~cm}^{-3}$ and $\mathrm{T}_{\mathrm{e}}=10 \mathrm{eV}$. Having $\left.<\sigma \mathrm{v}\right\rangle \equiv 2 \times 10^{-8} \mathrm{~cm}^{2} / \mathrm{s}$ from Locz's formula 39 and $\mathrm{V}_{3 v}$ $\equiv 5 \times 10^{5} \mathrm{~cm} / \mathrm{s}$, one can estimate $\lambda \equiv 12 \mathrm{~cm}$, leading to the conclusion that $\mathrm{R} \leq 10 \% .15$ This means that $\sigma_{d}{ }^{*}$ can be practically regarded as $\sigma_{d}$ within an accuracy of $10 \%$. Therefore, in the mresent paper, we would rather deal with $\sigma_{d^{*}}$ as measuref.

Typical desorption behavior of hydrogen under He-plasma bombardnemt at

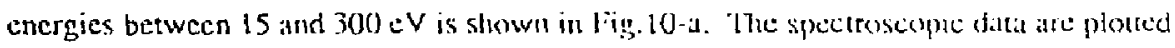

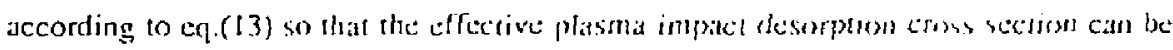

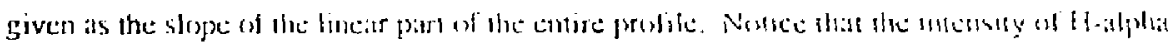

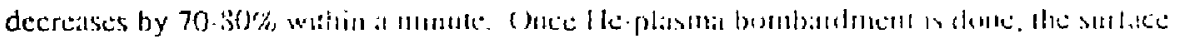
is reacrivisted. 
The characteristic desopion curves exhibit a significant deviation from t.. - prediction of eq. (13) in the plas.na bembardment fluence range above $=1 \times 10^{19}$ ions/cm 2 . Similar deviations have been observed in earlicr studies. $40-42$ There are several possibic causes for the deviation observed here. One simple possibility is that the assumption: $n_{\infty}$ " n to support eq.(10-c) might fail as desorption proceeds. However, the plasma bombardment fluence at which the deviation starts seems to be too small to cause the mathematical error. Another possibility is the retrapping effect on the disorption rate, as proposed by Wampler. ${ }^{40}$ This retrapping model can be described as follows: As ionimpact desorption proceeds, the number of unoccupied trapping sites increases. Consequently, detrapped hydrogen becomes more likely to be retrapped before it leaves the surface. The net desorption rate decreases, relative to that when there is no retrapping. The retrapping effect might in part contribute to the present result. Howerer, the depth of kinematic interaction between pre-implanted hydrogen and bembarding helium, which is $10-60 \AA$ (see Fig. 6), is somewhat too shallow to yield a significant retrapping effect of this kind.

Topographical effects on hydrogen release behavior are conjectured here for the sponge-like surface structure (see Fig. 3). As me:tioned earlier, a significant fraction of pre-implanted hydrogen is considered to reside in the pores. The in-pore hydrogen will undergo several collisions with the surface in the narro: pore channel before being ejected. This collisional process causes kinematical slow-down and eventually' leads to an in-pore retrapping. Also, it follows from this postulation that there will be no str. $g$ in-pore retrapping effect at the early stages of plasma impact desorption since hydrogen on the 'flat' surface area will be released predominanty, consistent with the observation.

\section{Evaluation of plasma-impact desorpuion cross sections}

The effective plasma impact desorption cross sections are deduced from the illitial inear pars shown in Fig. $\mathrm{O} 0 \mathrm{-b}$ and summarized in Fig. 11 as a funcrion of plastrat bombarding energy. In general, the ion impact desorption process is kinematically enhanced when implantition profiles for pre-implanted particles and for boubarding ions strongly overlitp. In the energy ringe cxasnited bere, the implameation profiles for helium

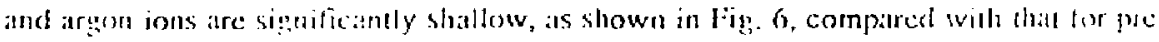

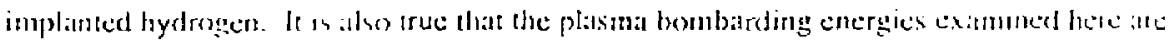

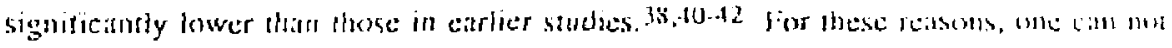

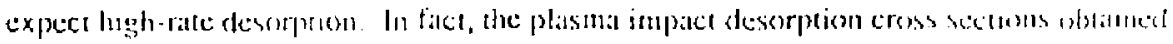


here are about one to two orders of magnitude below the existing data from ion beam experiment, conducted unde high-encrgy, overlapping deph-profile conditions. $35.94-12$

These argumerits indicate that He and Ar-plasma bombardment, particularly at nonsputtering energjes, will not kincmatically affect pre-implanted hydrogen below a certain depth. However, i: is found that the hydrogen-saturated grapinite surface can bc reactivated, via plasma impact desorption, regardless of the bombarding inergy examined here. This means that reactivated graphite can pump hydrogen plasma particles even if intamal trapping sites are occupied with pre-implanted hydrogen. It follows direct: from this that the bathtub concept cannot totally explain the plasma-pumping cipability of graphite. Rather, the activated sites on the sponge-like surface of graphite appear to play an important role in plasma-pumping phenor ina observed in the present work.

\section{Summary}

The effects of inert gas plasma bombardment on characteristics of isotropic ;:apluite have been investigated with respect to: (1) modification of the surface morohology: (2) surface gas-adsorptivity; (3) hydrogen plasma recycling; (4) surface chemicai ciosion, . $2 . .4$ (S) hydrogen release behavior.

The inert gas (He and Ar) plasma bombardment at energies between 100 and 200 $\mathrm{eV}$ at temperatures around $800^{\circ} \mathrm{C}$ strongly modifies the graphite surface via physical sputtering. Small graphite particles tlociing intrinsie pores are removed and the resultant graphite surface exhibits a significantly porous, sponge-like surface tnorphology. The surface mughness factor is roughty estimated to be 345 , noc surprising for such spongelike surfaces.

The activated graphite surface getters neutral residual gases in vacuum. The iniliat gettering speed is evaluated to be as large as 25 liters $s^{-1} \mathrm{~cm}^{-2}$, and the total getlering: capacity is 0.025 torr-liter $/ \mathrm{cm}^{2}\left(8.3 \times 10^{17}\right.$ molecules $\left./ \mathrm{cm}^{2}\right)$ at room temperanture. Afier saturation, the graphite surface can be easily reactivaled by iner gas plisma bornbardment. The nature of a activated graphite surface is attributed in part to the capillary thefecl of the sponge-like surface and surface radiation damage sitex.

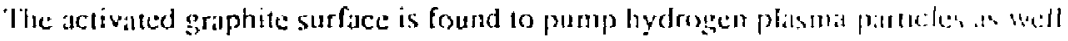

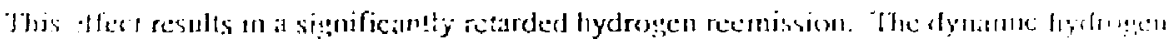

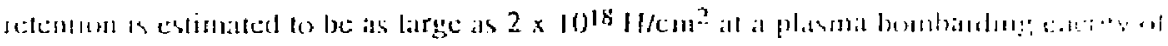

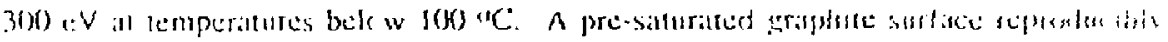

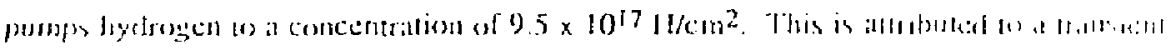


pumping capability associated with the sponge-like surface mophology of graplite. The transicnt plasma pumping is duc to a particle imbalance between fast implanation and slow release of hydrogen through pore channels. The net increase in hydrogen retention due to Hc-plasma activation appears to be close to the neutral gettering capacity, suggesting that the extra hydrogen is trapped on activated adsorptive surface sites. Also, the hydrogen retention capacity of graphite is found to decrease rapidly with increasing temperature. Al temperatures between 450 and $480^{\circ} \mathrm{C}$, the hydrogen retention estimated for the activated si'rface and pre-saturated surface is $7.9 \times 10^{17} \mathrm{H} / \mathrm{cm}^{2}$ and $2.7 \times 10^{17} \mathrm{H} / \mathrm{cm}^{2}$, respectively.

The surface chemical crosion rate during hydrogen recycling is found to track with hydrogen saturation. Consistently, the activated surface exhibits a reduced hydrocarbon formation and release rate, relative to the pre-saturated surface.

Hydrogen release under inert gas plasma bombardment is controlled by the plasma impact desorption process which may be influences by ia-pore retrapping. Hydrogen release from pre-saturated graphite under $\mathrm{He}$ and Ar plasma bombardment has been observed in a wide energy range from 15 to $300 \mathrm{sV}$. This result allows us to utilize the pjasma-impact desorption technique for wall conditioning in magnetic fusion devices. In fact, DC He-glow discharge without magnetic field has recently been used for surface conditioning in DIII-D tokamak, and has led to reduced local recycling $(R<1)$ at the graphite limiter area in several successive confinement experiments. 43

\section{ACKNOWLEDGMENTS}

Illaminating discussions with B.Bastasz and W.L.Hsu are appreciated. Spccial hanks go to K.Andrews, G.Gunner, V.Low, G.Ortuno, K.Sheedy and T.Skechely for their technical support. This work is supported by the Office of Fusion Encrgy. US Dipartment of Energy under contract \#DE-AT03-84ER52104. 


\section{RIEIIERI:NCIES}

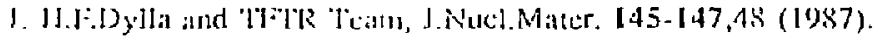

2. L. De Kouk, J.Nuel Matcr. 145-147, 26 (1987).

3. N.H.Brioks, P.Petersen and the DIIL-D group, J.Nucl.Mater. 145-147, 770 (1987).

4. J.Winter, I.Vac.Sci. \& Technol.-A 5, 2286 (1987).

5. M.Ulickson, I.L.Cecchi, B.Lipschultz, J.Vac.Sci.\&Technol.-A 5, 2257 (I987).

6. J.D.Strachan, M.Bitter, A.T.Rannsey et.al., Phys.Rev.Lelt. 58, 1004 (1987).

7. K.J.Dietz, K.Sonnenberg. E.Dekssis and R.Shaw, 'Wall Protection in JET', JET Rep. JET-P (85) 16

8. K.W.Hill, V.Arunasalm, M.G.Bell et.al., Proc.IAEA Ilth Int.Conf on Plasma Physics and Controlled Fusion Research. Kyoto. p. 207 (1986).

9. H.F.Dylla, P.H.LaMarche, M.Ulickson et.al., 'Conditioning of the Graphite Bumper Limiter for Enhanced Confinement Dishcarges in TFTR', PPPL Rep. PPPL-2448.

10. S.A.Cohen, J.Ehrenberg, T.T.C.Jones et.al., to be pu'-lished in Plasma Physics \& Conuolled Euston.

11. D.M.Goebel, Y.Hirooka, R.W.Conn et.al., J.Nucl.Mater. 145-147, 61 (1987).

12. A.E.Pontau, R.A.Causcy and J.Bohdansky, S.Nuch Mater. 145-147, 775 (1987).

13. K.Nakayama, S.Fukuda, T.Hino and T.Yankshina, J.Nucl.Mater. $145-147,301(1987)$.

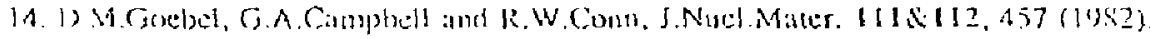

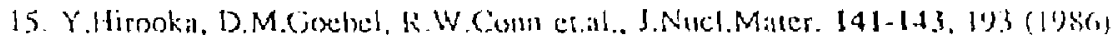

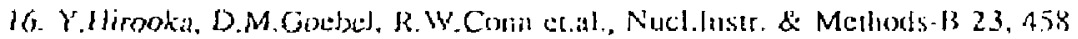
(14) 57 .

17. S.Dushman, Scientife Foundations of Vacuen Technique, 2nd ed.', Johu Wiley \& Sons, (1962).

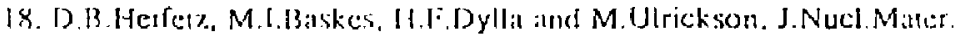
$1+5-147.326(1087)$

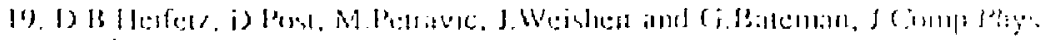
a6. Bn" (1982).

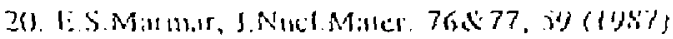

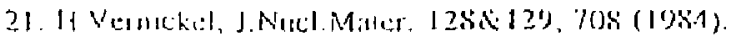


22. R. A.L.ungley, J.Johdansky, W.Eckstein et.al., 'Data Compendium for Plasma -Surtace Interactions', Seprecial Issue of Nucl. Fusion (1984).

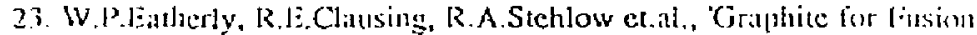
Energy Applications', ORNL, Rep. ORNL/TM-10280.

24. B.L.Doyle, W.R.Wanpler, D.K.Brice and S.T.Picraux, J.Nucl.Mater. o5\&94, $551(1980)$.

25. K.L.Wilson and W.L.Hsu, J.Nucl.Mater. 145-147, 121 (1987).

26. B.L.Doyle, J.Nucl.Mater. I11\& 112, 628 (1982).

27. Summarized in D.E.Post and R.Behrisch (ed.), 'Physics of Plasma-Wall Interactions in Controlled Fusion', NATO ASI-series vol. 131, Plenum Press (1986).

28. M.I.Baskes, 'DIFFUSE 83', SNL Rep. SAND83-8231.

29. J.P.Biersack and L.G.Haggmark, Nucl.Instr.\& Meth. 121, 257 (1980).

30. R.A.Langley, J.Vac.Sci.\&Technol.-A 5, 2205 (1987).

31. W.L.Hsu and R.A.Causey, J.Vac.Sci.\&Technol.-A 5, 2768 (1987).

32. R.A.Causey, M.I.Baskes and K.L.Wilson, J.Vac. Sci. and Technol.-A 4, 1189 (1986).

33. K.L.Wilson, A.E.Pontau, L.G.Haggmark et.al., J.Nucl.Mater. 103d 104, 493 (1981).

34. N.Matsumami, Y.Yamimaka, Y.Itikawa et.al., Atonic Data and Nucl.Data Tables $31.1(1984)$

3.5. C.M.Braganza, S K.Jüreats and G.M.MeCracken, J.Nucl.Mater.75, 220) (197\$)

36. R.Yamata, K.Nakimura, K.Sone and M.Saidoh, J.Nucl.Matur. 95. 278 (1980),

37. A.B.Ehrlards and W.D.Langer, 'Collisional Processes of Ifydrocardonst in Hydrones Plasmass, PPI'L, Rep. PPI'L-2477.

38. For exampic, A.Signira and K.Kannda, J.Nuct.Mater, 111 d. 112,812 (1982)

39. W.Lotz. 7cischrift fur Plysik 216, 241 (1968).

AO) W.R.Wampler and S.M.Myers, J.Nucl.Mater 1112:112,616 (1982).

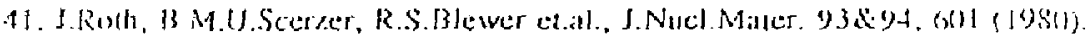

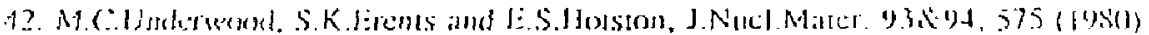

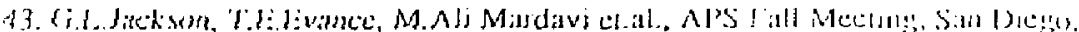
(1987). 


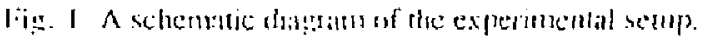

Fig. 2 A Iy, ical example ol observed behavior of ctrange of the cotal pressure in the PISCES-A facility after shut-down of helium plasma aperation for plasma activation of the graphite surface.

Fig. 3 Surface morphologies of the graphite target: (a) after ultrasonic cleaning in acetone and vacuum degassing at abour $800^{\circ} \mathrm{C}$; (b) after He-plasma activation; and (c) after extensive hydrogen recycling experiments.

Fig. 4 Hydrogen recycling behivior from the activated and pre-saturated graphite surfaces under H-plasina bombirdment at a flux of $1 \times 10^{18}$ ions $\mathrm{s}^{-1} \mathrm{~cm}^{-2}$ at an energy of $300 \mathrm{eV}$ and at temperatures below $1000 \mathrm{C}$. Experimental data atre interpolated by eq. $(\gamma)$ with the fitted characteristic une coustants.

Fig. 5 Comparison of hydrogen recyeling behavior computed with the DIFFUSE code 29 and that ohserved for an activated graphite under H-plasma bombardunest at a $\cap_{\mathrm{ux}}$ of $1 \times 10^{14}$ ions $\mathrm{s}^{-1} \mathrm{~cm}^{-2}$, at an cenergy of $300 \mathrm{eV}$ ands at temperantures inclow $10000 \mathrm{C}$.

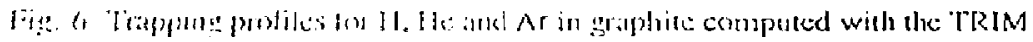

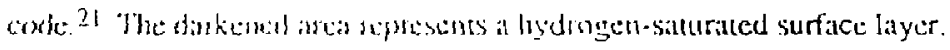

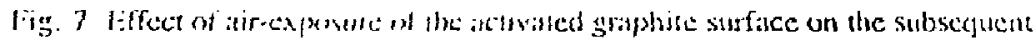

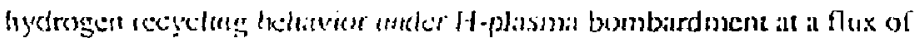

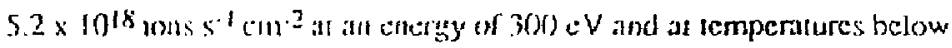
$1003 \times 5$

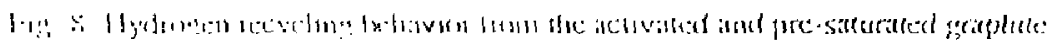

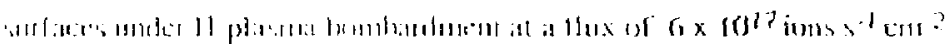

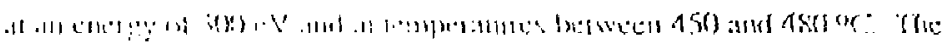

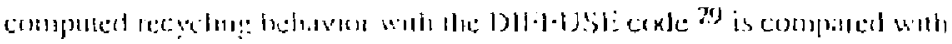

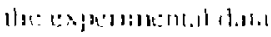




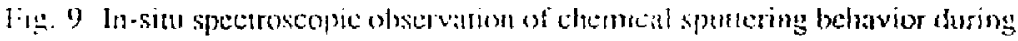
hyolrogen recyelisg under l-pilasmat tombathent at a flux of $5 \times 10^{17}$

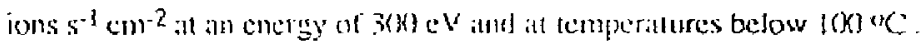

Fig-10 Hydrogen releisse behavior from pre-saturated graphite under He-plasmi bombardment at a constant flux of $1 \times 10^{18}$ ions s-1 $\mathrm{cm}^{-2}$ at energies berween 15 and $250 \mathrm{eV}$ to a fluence of $6 \times 10^{19} \mathrm{ions} / \mathrm{cm}^{2}$ (a) and to a fluence of $1 \times 10^{19}$ ions $/ \mathrm{cm}^{2}$ (b).

Fig. II Effective plasma impacr desorption cross sections for $\mathrm{H}, \mathrm{He}$ and At from graphite as a function of plasma bombarding energy. 


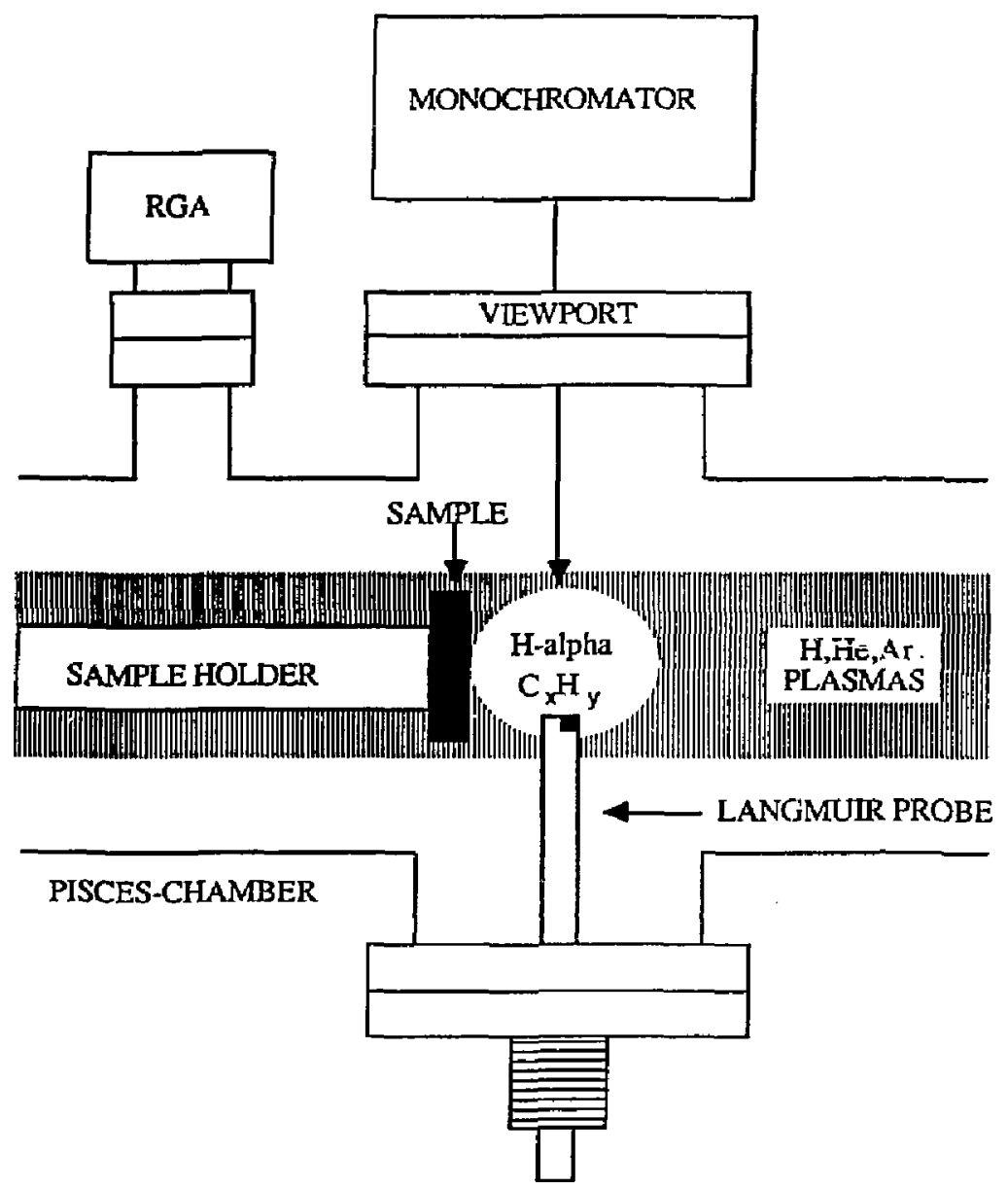

FIG. I 


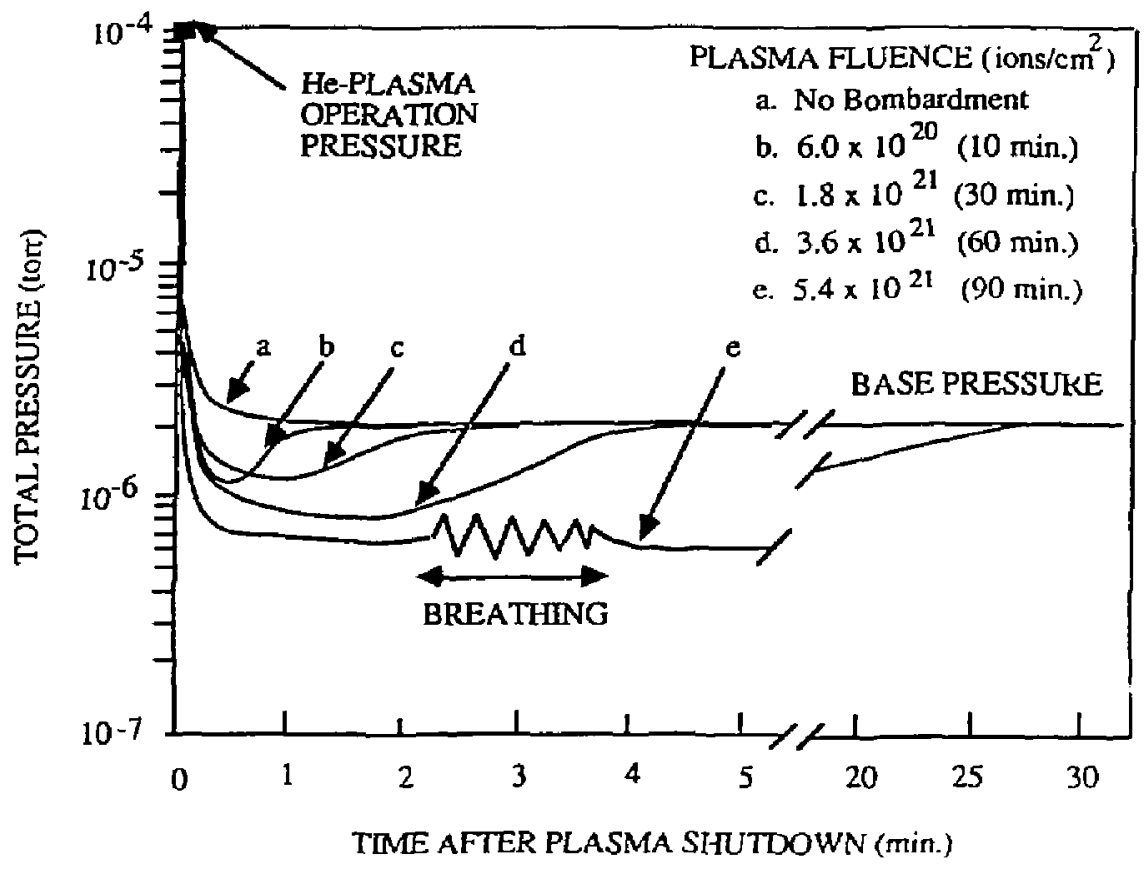

FIG. 2 

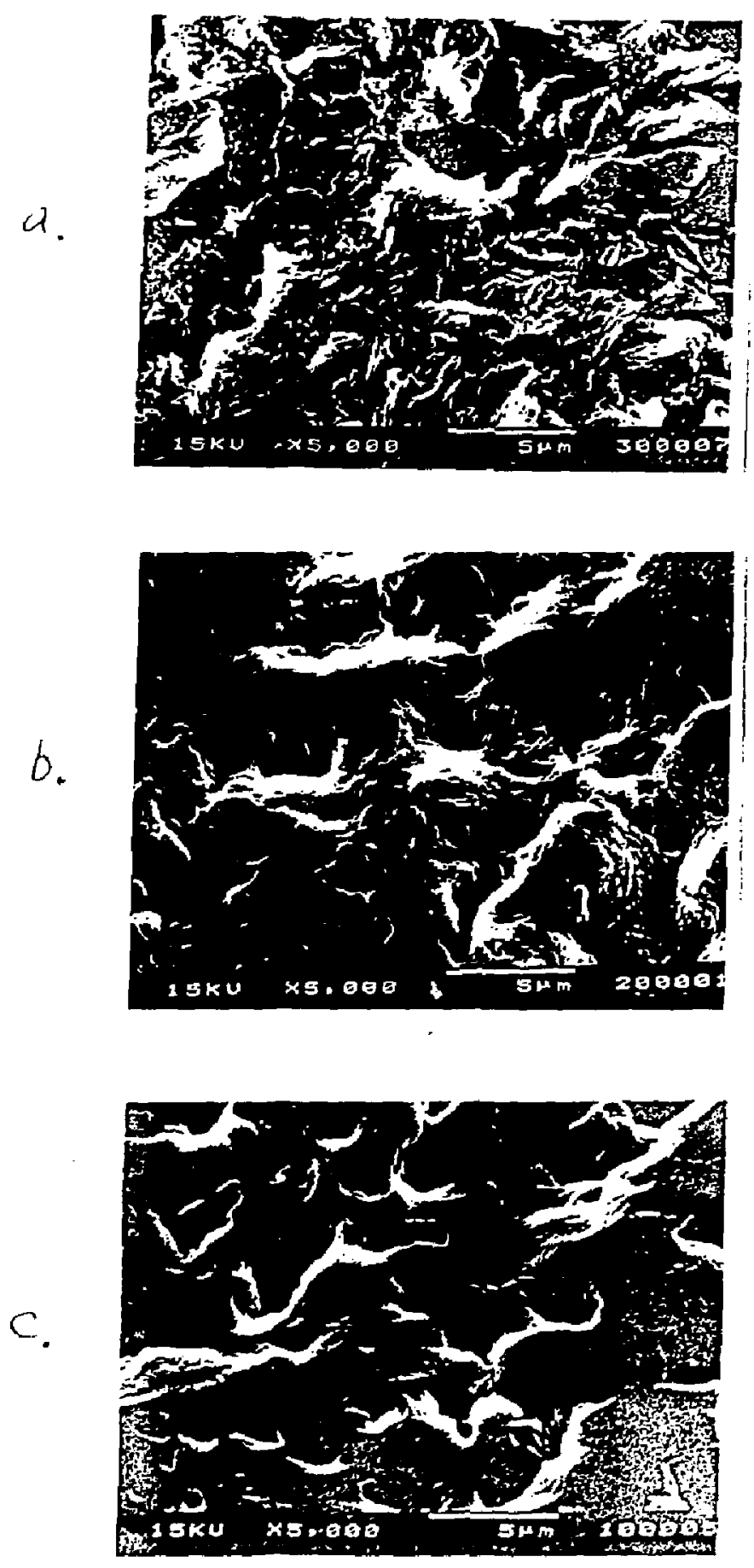

Fig. 3 


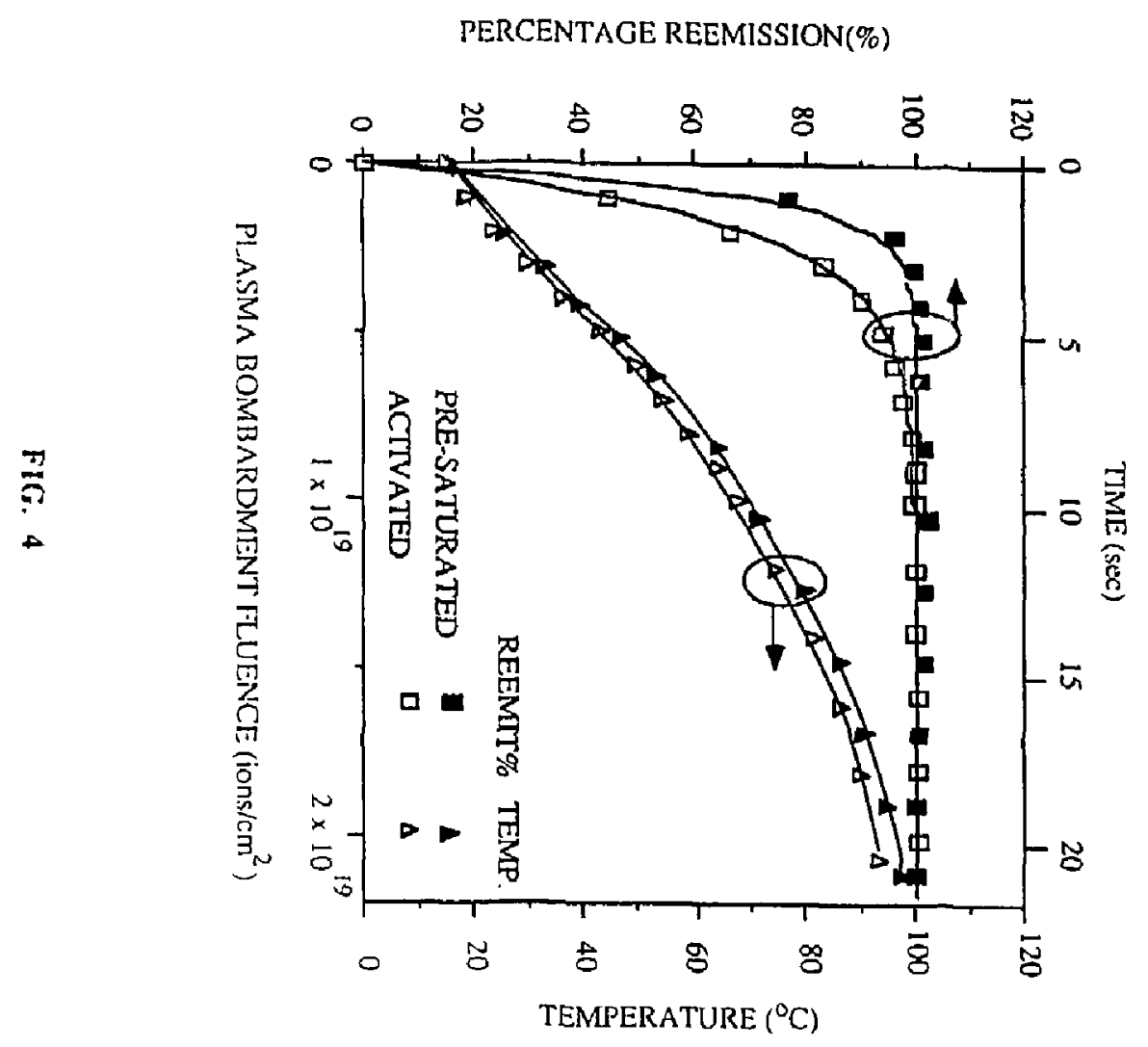




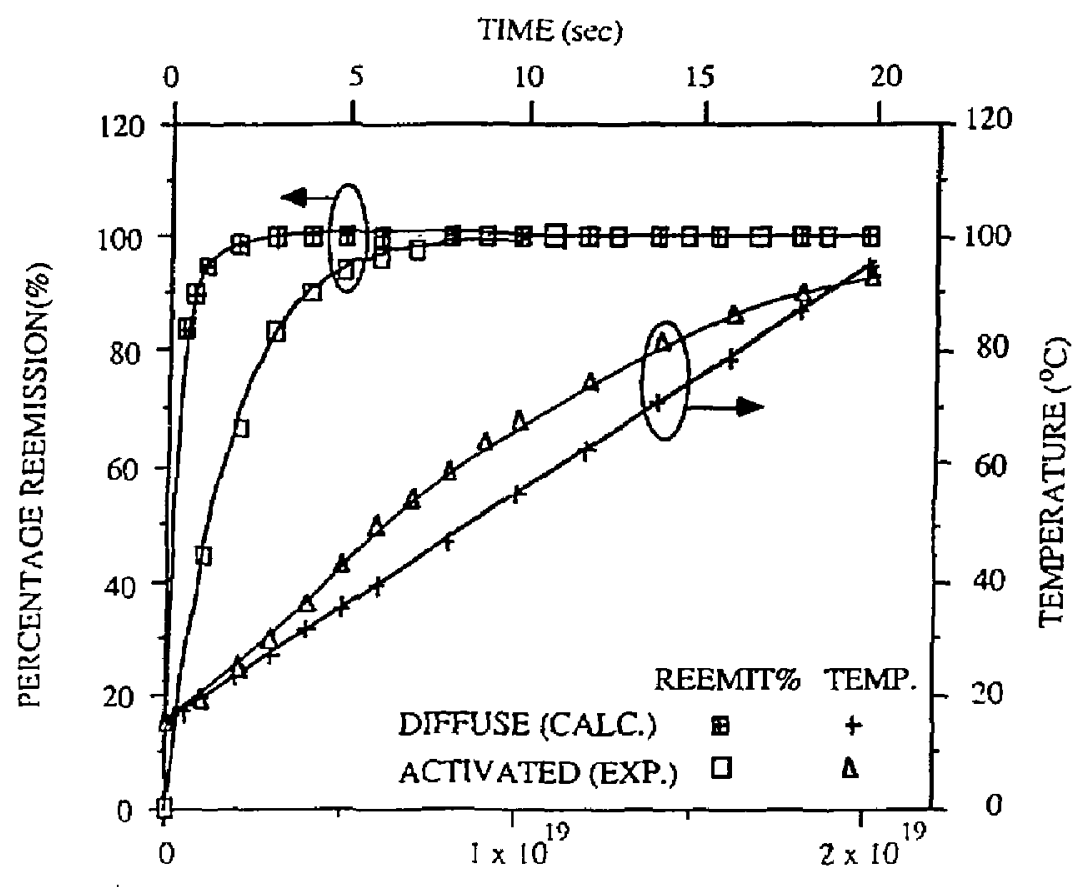

P. ASMA BOMBARDMENT FLUENLE (ions $/ \mathrm{cm}^{2}$ )

FIG. 5 


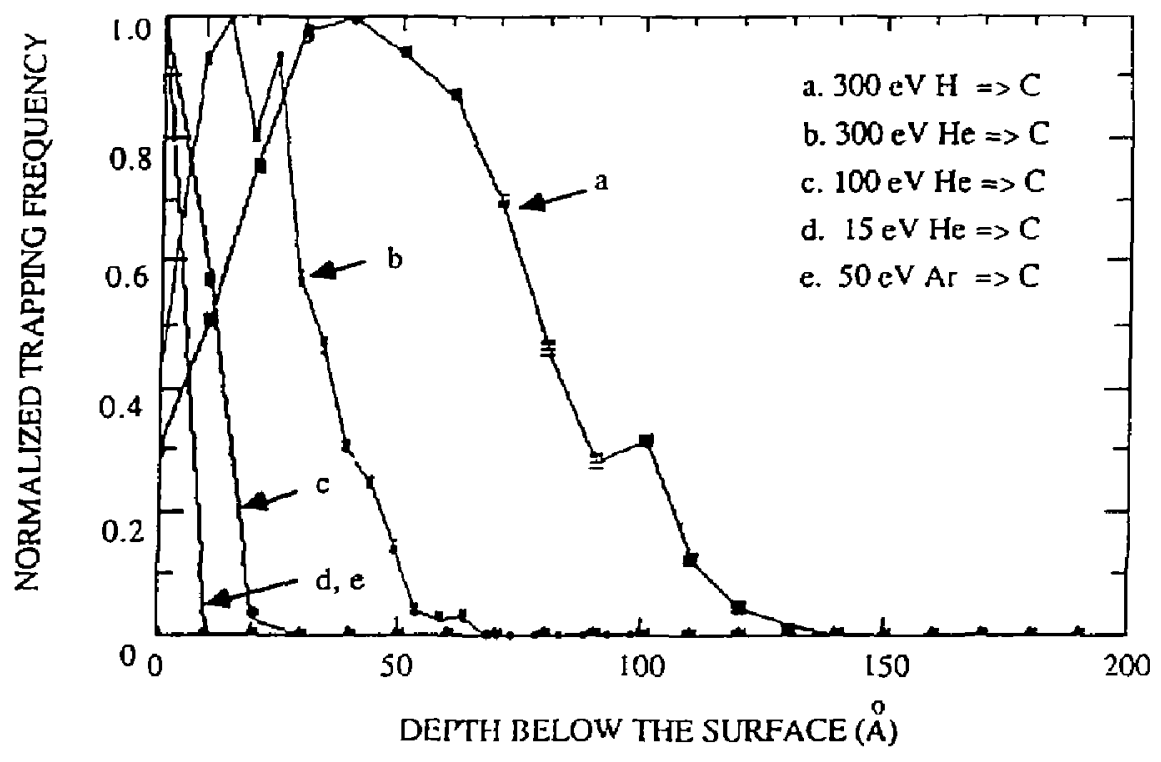

Fis, 6 


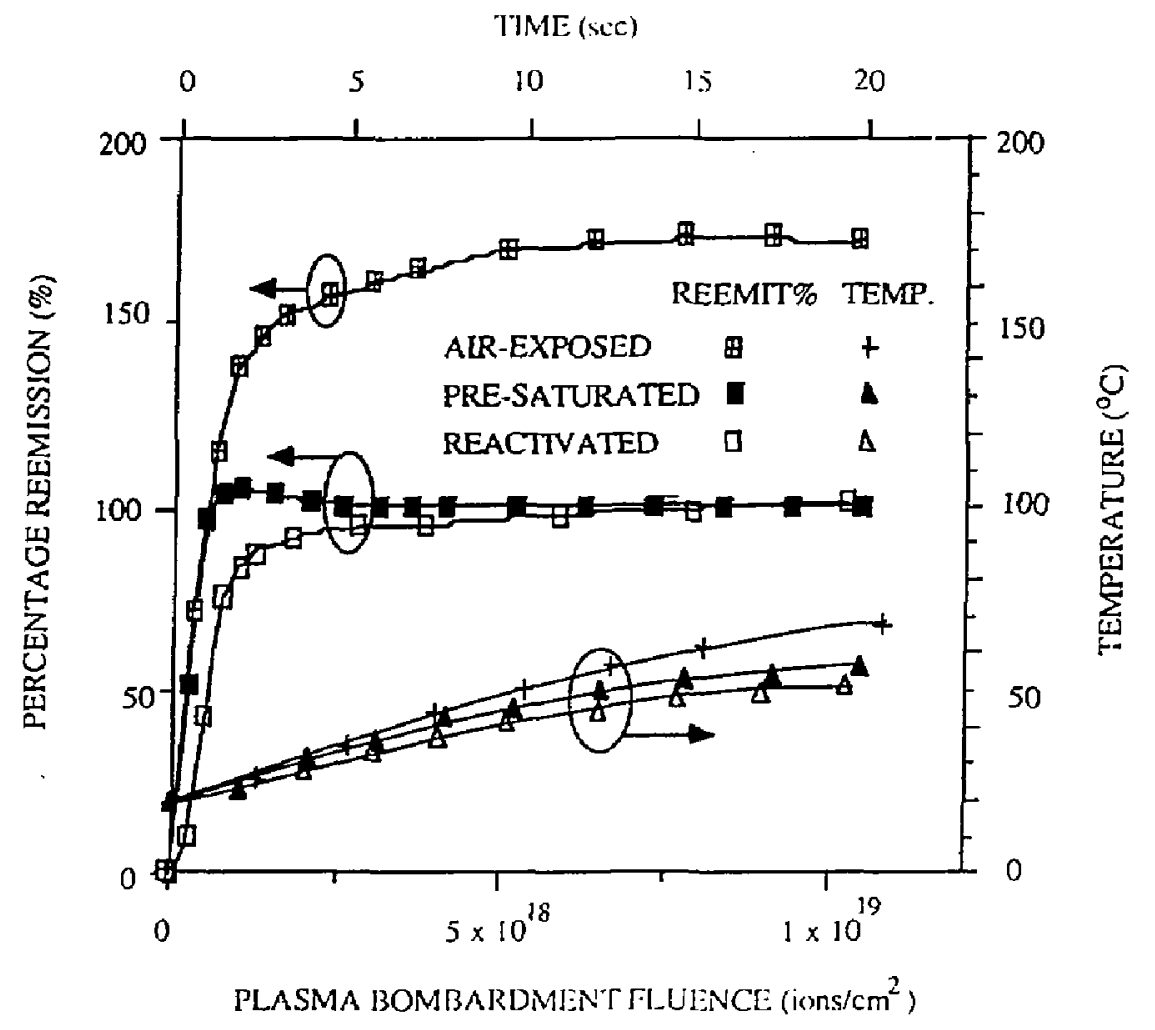

FIG. 7 


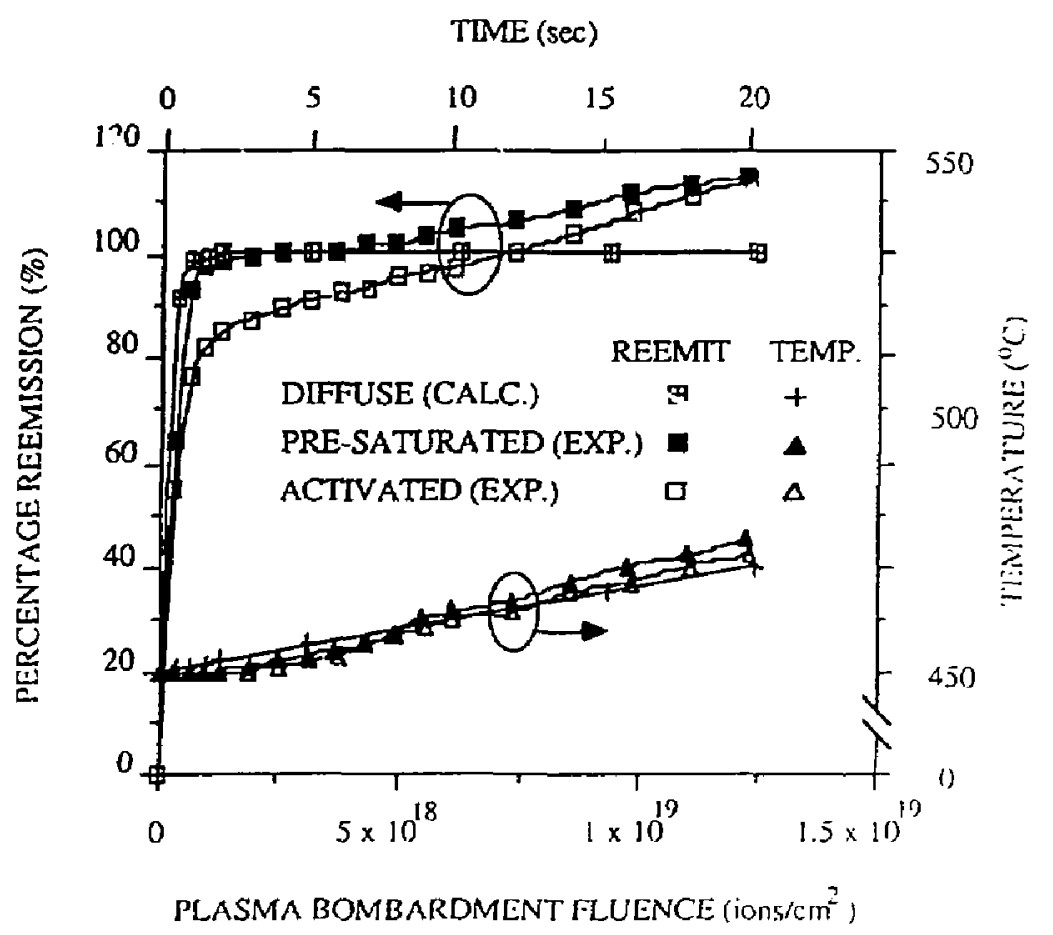

FIG. 8 


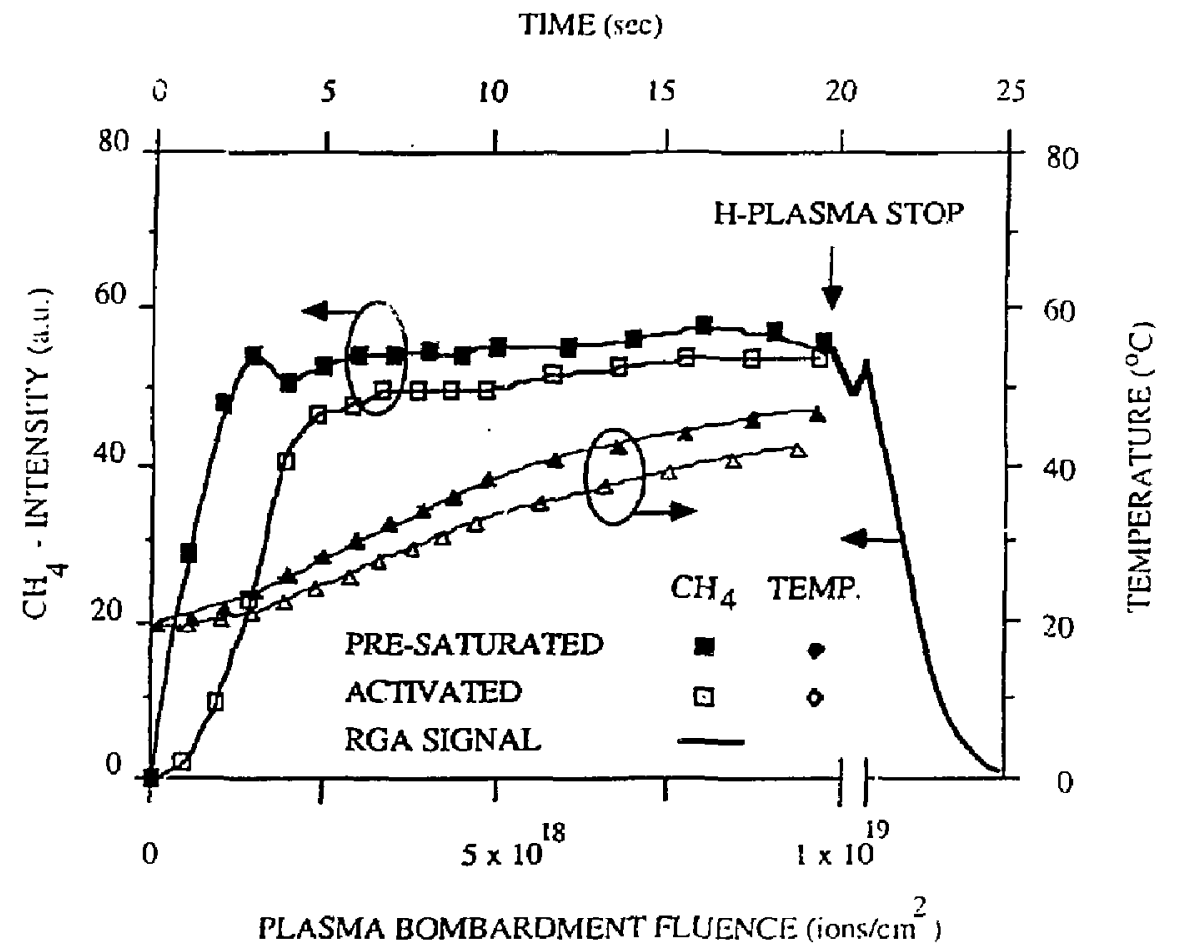

FIG. ) 


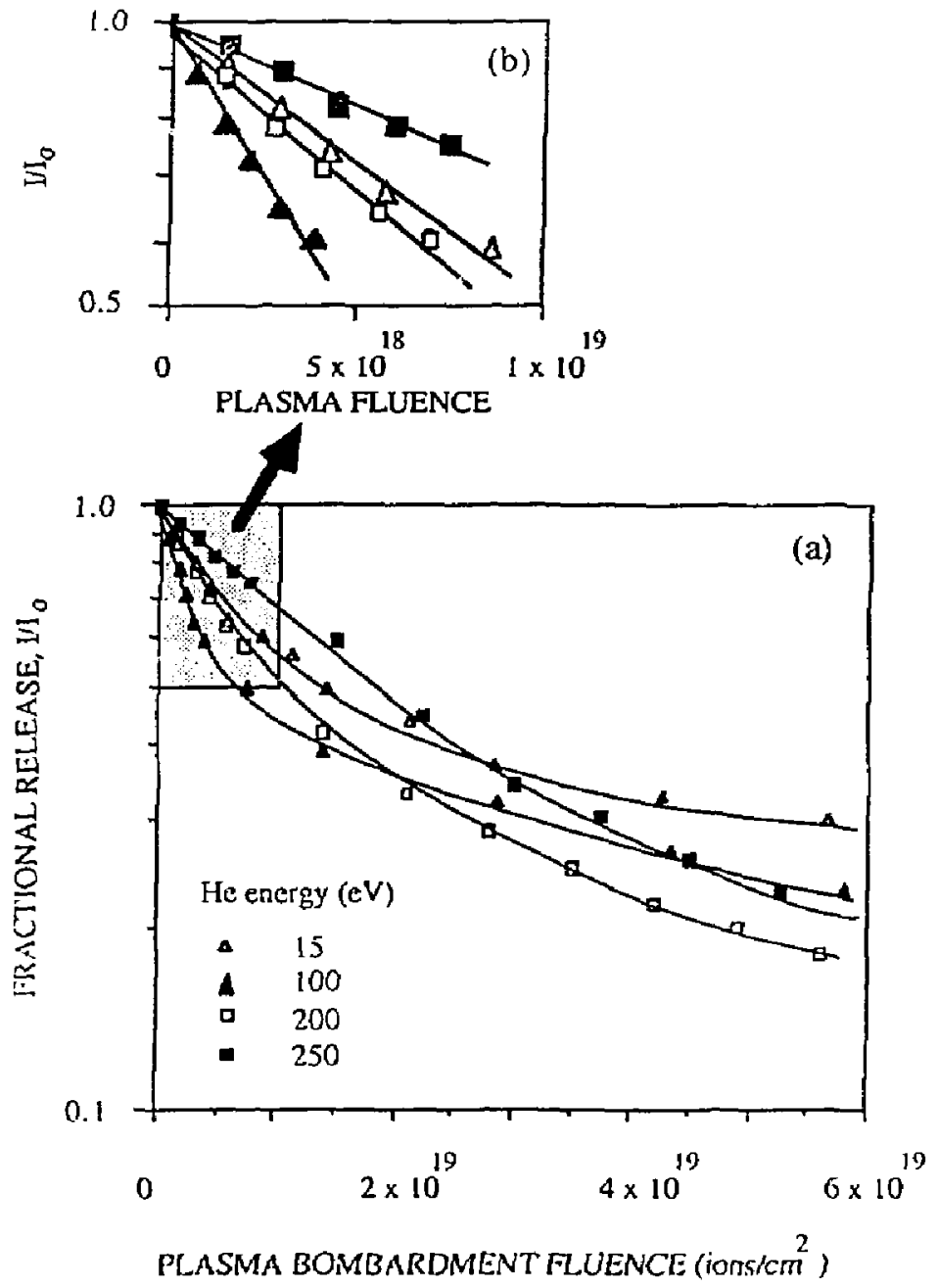

FIC. 10 


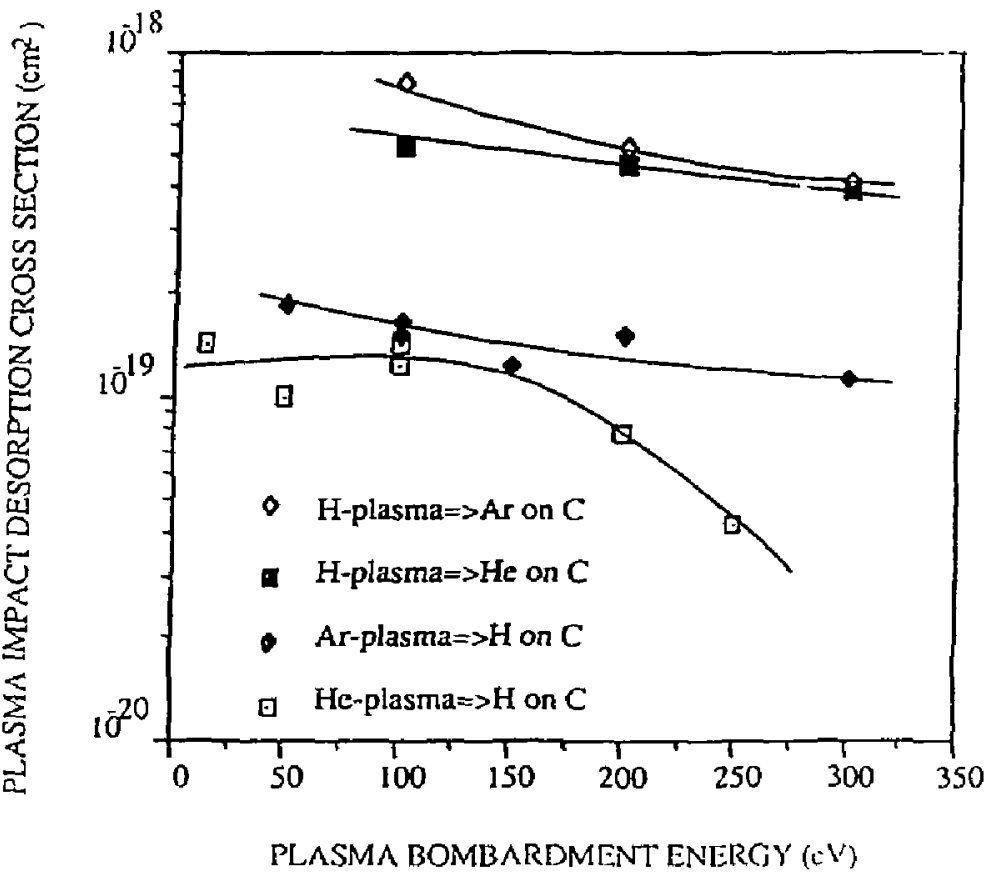

FIG. 11 